\title{
Probiotics or Synbiotics Addition in Bama Mini-pigs' Diets Improves Growth Performance, Carcass Traits, and Meat Quality by Altering Plasma Metabolites and Related Gene Expression of Offspring Pigs
}

\section{Qian Zhu}

Institute of Subtropical Agriculture Chinese Academy of Sciences

\section{Mingtong Song}

Institute of Subtropical Agriculture Chinese Academy of Sciences

Md. Abul Kalam Azad

Institute of Subtropical Agriculture Chinese Academy of Sciences

\section{Cui Ma}

Institute of Subtropical Agriculture Chinese Academy of Sciences

\section{Yulong Yin}

Institute of Subtropical Agriculture Chinese Academy of Sciences

Xiangfeng Kong ( $\square$ nnkxf@isa.ac.cn )

Institute of Subtropical Agriculture Chinese Academy of Sciences https://orcid.org/0000-0001-64066445

\section{Research Article}

Keywords: Bama mini-pigs, Carcass traits, Growth performance, Meat quality, Plasma metabolites, Probiotics, Synbiotics

Posted Date: October 26th, 2021

DOI: https://doi.org/10.21203/rs.3.rs-1000404/v1

License: (c) (i) This work is licensed under a Creative Commons Attribution 4.0 International License. Read Full License 
Probiotics or synbiotics addition in Bama Mini-pigs' diets improves growth performance, carcass traits, and meat quality by altering plasma metabolites and related gene expression of offspring pigs

Qian Zhu ${ }^{1,2}$, Mingtong Song ${ }^{1}$, Md. Abul Kalam Azad ${ }^{1}$, Cui Ma ${ }^{1,2}$, Yulong Yin ${ }^{1 *}$, Xiangfeng Kong ${ }^{1,2,3 *}$

${ }^{1}$ Hunan Provincial Key Laboratory of Animal Nutritional Physiology and Metabolic Process, Institute of Subtropical Agriculture, Chinese Academy of Sciences, Changsha, Hunan, China

${ }^{2}$ University of Chinese Academy of Sciences, Beijing, China

${ }^{3}$ Research Center of Mini-Pig, Huanjiang Observation and Research Station for Karst Ecosystems, Chinese Academy of Sciences, Huanjiang, Guangxi, China

* Correspondence:

Xiangfeng Kong,nnkxf@isa.ac.cn or Yulong Yin, yinyulong@isa.ac.cn 


\section{Abstract}

2 The present study evaluated the effects of maternal probiotics or synbiotics addition on

3 growth performance, carcass traits, meat quality, plasma metabolites, and related gene

4 expression of their offspring pigs. A total of 64 Bama mini-pigs were used and

5 randomly divided into the control, antibiotic, probiotics, or synbiotics groups, and fed

6 experimental diets during pregnancy and lactation. After weaning, two piglets per litter

7 and eight piglets per group were selected and fed a basal diet. At 65-, 95-, and 125-day-

8 old, eight pigs per group were selected for analysis. The results showed that probiotics

9 addition increased the ADFI of pigs during the 66-95 day-old and the backfat thickness

10 at 65- and 125-day-old, whereas synbiotics addition increased backfat thickness and

11 decreased muscle percentage and loin-eye area at 125-day-old. In meat quality,

12 probiotics or synbiotics addition increased cooking yield, $\mathrm{pH}_{45 \mathrm{~min}}$, and meat color, while

13 decreased drip loss and shear force at different stages. However, maternal antibiotic

14 addition showed an increased shear force at 125-day-old. Dietary probiotics or

15 synbiotics addition in sow diets increased several amino acids (AA) contents in the

16 plasma and longissimus thoracis (LT) muscle, including total AA (TAA), His, Met,

17 Asp, Arg, and Leu, while decreased Gly, Pro, Ile, $\alpha$-AAA, $\alpha$-ABA, $\beta$-Ala, and $\gamma$-ABA

18 at different stages. In the LT muscle fatty acid (FA) analysis, the contents of saturated

19 FA (SFA; including C16:0, C17:0, and C20:0) and C18:1n9t were decreased, and the

20 contents of C18:2n6c, MUFA (C16:1 and C20:1) and UFA were increased in the

21 probiotics group, while the contents of SFA (C10:0, C12:0, and C14:0 at 65-day-old) 
22 were increased and the contents of $\mathrm{C} 20: 1$ and $\mathrm{C} 18: 1 \mathrm{n} 9 \mathrm{t}$ were decreased in the synbiotics

23 group. Plasma biochemical analysis revealed that maternal probiotics or synbiotics

24 addition decreased plasma AMM, UN, and GLU, while synbiotics addition increased

25 plasma ALT, HDL-C, and TC at different stages. Moreover, maternal probiotics or

26 synbiotics regulated muscle fiber-type, myogenic regulatory, and lipid metabolism-

27 related gene expressions of offspring pigs. In conclusion, maternal probiotics or

28 synbiotics addition, as a nutritional intervention strategy, improved feed intake and

29 meat quality by altering the body's metabolism of offspring pigs and gene expressions

30 related to meat quality.

31 Keywords: Bama mini-pigs; Carcass traits; Growth performance; Meat quality; Plasma

32 metabolites; Probiotics; Synbiotics 


\section{Introduction}

Microbes inhabited in the gut have strong metabolic activity and play critical roles in regulating the growth and development, nutrient metabolism, immunity response, and health of the host [1]. Previous studies have shown that the intestinal microbiota can affect muscle growth, nutrient metabolism, and muscle fiber type transformation [2], indicating that intestinal microbiota can influence the carcass traits and meat quality through multiple metabolic pathways. Increasing evidence has shown that maternal probiotics supplementation has beneficial effects on offspring piglet's growth and development. For example, dietary Bacillus addition during late gestation and lactation has beneficial effects on growth performance and intestinal microbiota modulation of piglets [3]. In addition, dietary prebiotics such as xylo-oligosaccharides (XOS) intervention could also facilitate the proliferation of beneficial microbes and thus improve the growth performance of weaned piglets by regulating intestinal health [4]. However, it has remained unknown how maternal gut microbiota regulates the meat quality of offspring and whether the gut microbiota or their metabolites have positive effects on meat quality. Therefore, maternal gut microbiota intervention through probiotics, prebiotics, and synbiotics addition would be used as a strategy to improve the meat quality of the offspring.

1 Maternal health and nutritional status during gestation and lactation play a vital role in the growth and development of the fetuses and have potential long-term effects on offspring pigs. Studies have demonstrated that changing maternal nutrition during 
gestation and lactation can affect meat color, muscle tenderness, intramuscular fat (IMF), water-holding capacity, muscle fiber type, and muscle metabolism of offspring pigs $[5,6]$. Furthermore, fetal and neonatal periods are the most critical periods for skeletal muscle development, which has been completed in the embryonic and fetal stages [7]. The development of postnatal muscle fibers is dependent on the increased diameter and alteration of muscle fiber type composition [8]. Therefore, pregnancy and lactation stages are the window periods to regulate the development of fetal muscle fibers and meat quality. In other words, maternal nutrition intervention during pregnancy and lactation is an effective strategy to improve the growth and development of fetal skeletal muscle and meat quality of offspring pigs.

Our previous studies showed that the addition of maternal synbiotics (including Lactobacillus plantarum $\geq 1.0 \times 10^{8} \mathrm{CFU} / \mathrm{g}$, Saccharomyces cerevisiae $\geq 0.2 \times 10^{8}$ CFU/g and XOS) during pregnancy and lactation improved piglet's survival rate, nutrient metabolism, and intestinal barrier permeability, reduced oxidative stress, and modified colonic microbiota composition and metabolic activity in suckling piglets [9, 10]. Based on the above-mentioned findings, we hypothesize that the intervention in the intestinal microbial balance of sows by dietary probiotics or synbiotics might improve the growth performance and meat quality of offspring pigs. Bama mini-pig, as one of the most well-known native mini-pigs in China, has better meat quality and lower muscle growth than commercial pigs [11]. In addition, the Bama mini-pig is a useful animal model for studying high-quality meat. Therefore, the present study used Bama 
mini-pig as a model to explore the effects of maternal antibiotic (inhibiting the gut microbiota), probiotics (increasing the beneficial gut microbiota), or synbiotics (increasing the beneficial gut microbiota and their fermenting substrate) addition during pregnancy and lactation on growth performance, carcass traits, meat quality, plasma metabolites, and related gene expression of offspring pigs.

\section{Materials and methods}

\section{Animals, diets, and treatments}

The present study was conducted at the mini-pig experimental base of Goat Chong located in Shimen Town, Changde City, Hunan Province, China. A total of 64 pregnant Bama mini-pigs during 3-5 parities with initial body weight (BW) of about $90 \mathrm{~kg}$ were selected and randomly divided into four groups (16 sows (pens) per group). The dietary treatment groups were represented the control group (fed antibiotic-free basal diet), antibiotic group (added $50 \mathrm{~g} / \mathrm{t}$ virginiamycin with the basal diet), probiotics group (added $200 \mathrm{~mL} / \mathrm{d}$ probiotics mixture per animal with the basal diet), and synbiotics group (added $500 \mathrm{~g}$ XOS per ton diet $+200 \mathrm{~mL} / \mathrm{d}$ probiotics mixture per animal with the basal diet). The probiotics mixture was provided by Hunan Lifeng Biotechnology Co., Ltd. (Changsha, Hunan, China), containing Lactobacillus plantarum $\geq 1 \times 10^{8}$ $\mathrm{CFU} / \mathrm{mL}$ and Saccharomyces cerevisiae $\geq 0.2 \times 10^{8} \mathrm{CFU} / \mathrm{mL}$. The XOS was provided by Shandong Longlive Biotechnology Co., Ltd. (Shandong, China), containing xylobiose, xylotriose, and xylotetraose at $\geq 35 \%$. The supplementing probiotics mixture was mixed with diets before feeding the sows, and the XOS was added to diets during 

by the manufacturers.

After insemination, the sows were housed individually in gestation crates $(2.2 \times$ $0.6 \mathrm{~m}$ ) from day 1 to day 105 of pregnancy. The sows were then transferred to farrowing crates $(2.2 \times 1.8 \mathrm{~m})$ on day 106 of pregnancy, where they were housed until weaning.

101 The sows were fed $0.8,1.0,1.2,1.5$, and $2.0 \mathrm{~kg}$ of the pregnant diets during $1-15,16-$ 30, 31-75, 76-90, and 91-105 days of pregnancy, respectively; fed $1.0 \mathrm{~kg}$ pregnant diets

103 before a week of parturition and ad libitum after three days of parturition; and then fed $1042.4 \mathrm{~kg}$ lactation diets until weaning. The sows were fed twice daily at 8:00 a.m. and 105 5:00 p.m., respectively, and water was freely available at all times. The creep feed was 106 provided to the suckling piglets from 7- to 28-day-old. After weaned at 28-day-old, one 107 male piglet and one female piglet close to the average BW per litter were selected and 108 transferred to the nursery house for the subsequent feeding trial. After one week of 109 adaption, four piglets from two litters in the same group were merged into one pen.

110 Four piglets were assigned to one pen with eight pens (replicates) per group. All the

111 piglets were fed the basal diet of the remaining trial. Basal diet composition and nutrient

112 levels for the sows and piglets are presented in Supplementary Table $\mathbf{1}$ and

113 Supplementary Table 2, respectively. Feeding and management were carried out

114 according to the standard operation of commercial pig farms.

\section{Sample collection}


116 The offspring pigs from each group were fasted for $12 \mathrm{~h}$ and weighed at 65-, 95-, and

117 125-day-old, respectively. Then one pig per pen (a total of eight pigs per group) was

118 selected and sacrificed under commercial conditions using electrical stunning (120 V,

$119200 \mathrm{HZ}$ ) and exsanguination. Blood samples were collected via precaval vein in $10 \mathrm{~mL}$

120 heparinized tubes, centrifuged at $4^{\circ} \mathrm{C}$ and $3,500 \times g$ for 10 min to obtain plasma, and

121 immediately stored at $-20^{\circ} \mathrm{C}$ for further analysis. After removing the head, legs, tail,

122 and viscera, the carcass was split longitudinally for evaluating carcass traits and meat

123 quality. Then the longissimus thoracis (LT) muscle samples were collected, and stored

124 in sealed plastic bags at $-20^{\circ} \mathrm{C}$ to analyze the routine nutrients. In addition, the LT

125 muscle samples $(\sim 2 \mathrm{~g})$ were also collected and immediately frozen in liquid nitrogen

126 and stored at $-80^{\circ} \mathrm{C}$ for mRNA analyses.

127 Determination of growth performance

128 Feed intake of offspring pigs per pen was recorded daily. The BW of all pigs per pen

129 was weighed at 65-, 95-, and 125-day-old pigs, respectively. The average daily gain

130 (ADG), average daily feed intake (ADFI), and feed/gain ratio (F/G) were calculated

131 during 35-65, 66-95, and 96-125 day-old, respectively.

132 Measurement of carcass traits

133 According to the Chinese pig-raising industry standards (GB8467-87, 1988), the left

134 side of each carcass was dissected into the skin, skeletal muscle, bone, and fat. The

135 skeletal muscle, bone, fat, and leaf fat were weighted for calculating their percentages

136 of live BW [tissue weight $\times 2(\mathrm{~kg}) / \mathrm{BW}(\mathrm{kg}) \times 100 \%$ ] or ratio to live $\mathrm{BW}$ [leaf fat weight 
138 using a Vernier caliper. The width and height of the LT muscle cross-section were

139 measured using a Vernier caliper for calculating the loin-eye muscle area (width $\times$

140 height $\times 0.7)$.

\section{Measurement of meat quality}

142 The subjective marbling and meat color scores of the LT muscle were determined by

143 following the National Pork Producers Council (NPPC) guidelines [12]. Meat color,

144 including $\mathrm{L}^{*}$ (lightness), $\mathrm{a}^{*}$ (redness), and $\mathrm{b}^{*}$ (yellowness) values of the LT muscle

145 were measured using the colorimeter (CR410, Konica Minolta Sensing, Inc., Tokyo,

146 Japan) at 45 min post mortem. The $\mathrm{pH}$ at $45 \mathrm{~min}\left(\mathrm{pH}_{45 \min }\right)$ and $24 \mathrm{~h}\left(\mathrm{pH}_{24 \mathrm{~h}}\right)$ post mortem

147 was measured by using a portable $\mathrm{pH}$ meter (Russell CD700, Russell pH Limited,

148 Germany). The drip loss was determined using the "bag method" as previously

149 described [13]. Briefly, the LT muscle samples were stored at $4^{\circ} \mathrm{C}$, and then the samples

150 were placed in individual polyethylene vacuum bags and cooked to an internal

151 temperature of $70^{\circ} \mathrm{C}$ detected by the thermocouple thermometer (Digital Thermometer

152 TP101, Changzhou KB Instruments \& Meter Co., Ltd., China) in a water bath at $75^{\circ} \mathrm{C}$

153 at $24 \mathrm{~h}$ post mortem [14]. Then the cooked samples were cooled to room temperature,

154 dried with a paper towel, and re-weighted for calculating cooking yield [(cooked

155 weight/fresh weight $) \times 100 \%$ ]. After the cooking yield determination, the samples were

156 trimmed into shaped stripes with a diameter of $1.27 \mathrm{~cm}$ and a length of $20 \mathrm{~mm}$ along

157 the direction parallel to the muscle fiber. The stripes were then used to determine the 

shear force (N) using a texture analyzer (FTC-TMS/PRO, FTC Corporation, United

159 States) with a load cell of $15 \mathrm{~kg}$ and a $200 \mathrm{~mm} / \mathrm{min}$ crosshead speed.

\section{Chemical composition analysis of the longissimus thoracis muscle}

161 The LT muscle samples were minced after weighing and dried in a vacuum-freeze dryer

162 at $(20 \pm 5) \mathrm{Pa}$ and $-(45 \pm 5){ }^{\circ} \mathrm{C}$ for $72 \mathrm{~h}$ (CHRIST RVC2-25 CDPIUS, Christ Company,

163 Oster ode, Germany) to calculate the dry matter (DM) content. The crude protein (CP)

164 content $(\mathrm{N} \times 6.25)$ was determined using the Kjeldahl method following the standards

165 provided by the Association of Official Analytical Chemists' (AOAC) methods [15].

166 The intramuscular fat (IMF) content was determined using the Soxhlet extraction 167 method [16].

168 Approximately $0.1000 \mathrm{~g}$ of freeze-dried skeletal muscle powder was hydrolyzed

169 in $10 \mathrm{~mL}$ of $6 \mathrm{~mol} / \mathrm{L} \mathrm{HCl}$ solution in a sealed ampoule bottle at $110^{\circ} \mathrm{C}$ for $24 \mathrm{~h}$. The

170 suspension was diluted to $100 \mathrm{~mL}$ using double-distilled water in the volumetric flask

171 [17], and $1 \mathrm{~mL}$ of the supernatant was transferred to $1.5 \mathrm{~mL}$ centrifuge tubes and

172 evaporated to dryness in a water bath at $65^{\circ} \mathrm{C}$. The samples were then dissolved using

$1731 \mathrm{~mL}$ of $0.02 \mathrm{~mol} / \mathrm{L} \mathrm{HCl}$ solution and filtered through a $0.45-\mu \mathrm{m}$ membrane prior to

174 analysis of hydrolyzed amino acids contents by an automatic amino acid analyzer (L-

175 8900, Hitachi, Tokyo, Japan) [18].

176 Medium- and long-chain fatty acids (FA) were identified via the gas-liquid

177 chromatography (7890A, Agilent, California, USA). Briefly, FA were analyzed by FID

178 detector after extracting with the mixture of benzene and petroleum ether and methyl 
esterification through potassium hydroxide methanol. The sample pretreatment method

180 was described as previously [19]. The GC conditions were as follows: the injector and

181 detector temperatures were held at $280^{\circ} \mathrm{C}$; the initial column temperature held at $100^{\circ} \mathrm{C}$

182 for $13 \mathrm{~min}$; increased at $10^{\circ} \mathrm{C}$ per min to $180^{\circ} \mathrm{C}$, and held for $6 \mathrm{~min}$; increased at $1^{\circ} \mathrm{C}$

183 per min to $200^{\circ} \mathrm{C}$, and held for $20 \mathrm{~min}$; increased at $4^{\circ} \mathrm{C}$ per min to $230^{\circ} \mathrm{C}$, and held for

$18415 \mathrm{~min}$. Nitrogen was used as the carrier gas and the flow rate was $0.8 \mathrm{~mL} / \mathrm{min}$. The

185 inlet temperature was $270^{\circ} \mathrm{C}$, the injection volume was $1 \mu \mathrm{L}$, and the split ratio was

186 20:1. The contents of FA were identified by comparison with the retention times of

187 reference standard mixtures (99\%, Sigma, St. Louis, MO, USA). Data are expressed as

188 the percentage of the total FA.

\section{Muscular RNA extraction and real-time quantitative PCR analysis}

190 Total RNA of the LT muscle was extracted using the AG RNAex Pro reagent (Accurate

191 Biology, Hunan, China) according to the manufacturers' protocol. The concentration

192 of the extracted RNA was measured using the NanoDrop ND-2000 spectrophotometer

193 (Thermo Fisher Scientific, Waltham, MA, United States), and the purity was

194 ascertained by the A260/A280 ratio. The quality of RNA was evaluated with agarose

195 gel electrophoresis. The total RNA (1000 ng) was reversely transcribed into cDNA

196 using an Evo M-MLV RT Kit with gDNA Clean for qPCR (Accurate Biology, Hunan,

197 China). The RT-PCR analysis was performed on the LightCycler ${ }^{8}$ 480II Real-Time

198 PCR System (Roche, Basel, Swiss) with SYBR ${ }^{\circledR}$ Green Premix Pro Taq HS qPCR Kit

199 (Accurate Biology, Hunan, China). The specific primers of target genes were designed 
201 Table 3). The RT-qPCR was performed in a $10 \mu \mathrm{L}$ reaction system, including $0.25 \mu \mathrm{L}$ 202 of each primer, 5.0 $\mu \mathrm{L} \mathrm{SYBR}{ }^{\circledR}$ Green Premix, $2.0 \mu \mathrm{L}$ cDNA, and $2.5 \mu \mathrm{L}$ of double203 distilled water. The PCR cycling conditions were followed according to the instructions 204 of SYBR Green Premix. The relative gene expression levels between different groups 205 were calculated using the $2^{-\triangle \Delta \mathrm{Ct}}$ method [20].

\section{Determination of plasma biochemical parameters}

207 The plasma levels of alanine aminotransferase (ALT), alkaline phosphatase (ALP), $\alpha-$ 208 amylase ( $\alpha$-AMS), aspartate aminotransferase (AST), cholinesterase (CHE), lactate 209 dehydrogenase (LDH), albumin (ALB), ammonia (AMM), total protein (TP), urea 210 nitrogen (UN), high-density lipoprotein-cholesterol (HDL-C), low-density lipoprotein211 cholesterol (LDL-C), total cholesterol (TC), triglyceride (TG), and glucose (GLU) were

212 determined using commercially available kits (F. Hoffmann-La Roche Ltd, Basel, 213 Switzerland) and the Roche automatic biochemical analyzer (Cobas c311, F. 214 Hoffmann-La Roche Ltd, Basel, Switzerland).

215 Determination of plasma free amino acids

216 The plasma samples $(800 \mu \mathrm{L})$ were mixed with $8 \%$ sulfosalicylic acid in equal 217 proportion, and then stored at $4^{\circ} \mathrm{C}$ for overnight to precipitate protein. The supernatants 218 were obtained by centrifuging at $8,000 \times g$ for $10 \mathrm{~min}$. The processed samples were 219 then filtered through a $0.22-\mu \mathrm{m}$ membrane into sample bottles prior to analysis of free 220 amino acids with an automatic amino acid analyzer (L8900, Hitachi, Tokyo, Japan). 


\section{Statistical analysis}

222 The experimental unit was a pen for the ADFI, ADG, and F/G data, and the individual

223 pig was for the other data. All data were analyzed using the SPSS software package

224 (SPSS v. 25.0, SPSS Inc., Chicago IL, USA). The normal distribution of the data was

225 confirmed by the Shapiro-Wilk test before assessing the differences among the four

226 groups. The data were analyzed by one-way ANOVA, and differences among the four

227 treatments were compared using the Tukey post-hoc test. Data are presented as means

228 with their standard error of the mean (SEM). Differences were considered significant if

$229 P<0.05$

230 Results

231 Growth performance

232 The effects of probiotics and synbiotics addition in sow's diets on growth performance

233 are shown in Table 1. Compared with the antibiotic group, dietary probiotics addition

234 in sow diets increased $(P<0.05)$ the BW of 95 -day-old offspring pigs. The ADFI was

235 increased in the probiotics group while decreased in the antibiotic group during 66-95

236 day-old, when compared with the control group $(P<0.05)$. Moreover, the antibiotic

237 group had higher F/G compared with the control group and higher ADFI compared with

238 the other three groups during 96-125 day-old $(P<0.05)$.

\section{Carcass traits}

240 The carcass traits of offspring pigs are presented in Table 2. At 65-day-old, the

241 probiotics group had a higher $(P<0.05)$ carcass weight compared with the antibiotic 
and synbiotics groups, while the backfat thickness was increased $(P<0.05)$ in the

243 probiotics group compared with the control and antibiotic groups. At 95-day-old, the

244 leaf fat ratio was lower $(P<0.05)$ in the antibiotic and probiotics groups compared with

245 the control and synbiotics groups, while the loin-eye area was higher $(P<0.05)$ in the

246 synbiotics group compared with the antibiotic group. Moreover, the antibiotic group

247 had a lower fat percentage than the other three groups and lower carcass weight than

248 the control group at 95-day-old $(P<0.05)$. At 125-day-old, dietary antibiotic, probiotics,

249 and synbiotics addition increased the fat percentage and backfat thickness, while dietary

250 synbiotics addition decreased the muscle percentage of pigs compared with the pigs in

251 the control group $(P<0.05)$. Moreover, dietary synbiotics addition decreased $(P<0.05)$

252 the loin-eye area of pigs compared with the three groups at 125-day-old.

\section{Meat quality}

254 The effects of dietary probiotics and synbiotics addition in sow diets on meat quality of

255 offspring pigs are shown in Table 3. Compared with the control and antibiotic groups,

256 drip loss in the probiotics and synbiotics groups was lower $(P<0.05)$, while cooking

257 yield in the probiotics group was higher $(P<0.05)$ at 65 -day-old. In addition, the $\mathrm{L}^{*}$

258 value was higher $(P<0.05)$ in the probiotics group, and the shear force was lower $(P<$

259 0.05) in the synbiotics group compared with the other three groups at 65-day old. At

260 95-day-old, the $\mathrm{a}^{*}$ value was lower $(P<0.05)$ in the probiotics group but was higher

$261(P<0.05)$ in the synbiotics group compared with the control and antibiotic groups, and

$262 \mathrm{pH}_{45 \min }$ was higher $(P<0.05)$ in the probiotics group compared with the control and 
synbiotics group. Moreover, the $\mathrm{L}^{*}$ value in the probiotics group was higher $(P<0.05)$

264 than the synbiotics groups at 95-day-old. At 125-day-old, the L* value was lower in the 265 synbiotics group compared with the control and probiotics groups, while the $b^{*}$ value 266 was higher in the probiotics group compared with the antibiotic and synbiotics groups $267(P<0.05)$. Moreover, the shear force in the probiotics and synbiotics groups was lower 268 than the control and antibiotic groups, while cooking yield and shear force were higher 269 in the antibiotic group than the other three groups at 125-day-old $(P<0.05)$.

\section{Amino acid contents of longissimus thoracis muscle}

271 The contents of amino acids in the LT muscle are presented in Table 4. Compared with

272 the control and antibiotic groups, His content in the LT muscle was higher in the 273 probiotics and synbiotics groups, while asparagine (Asp) and glycine (Gly) contents 274 were lower in the probiotics group at 65 -day-old $(P<0.05)$. At 95-day-old, compared 275 with the control group, arginine (Arg) content in the LT muscle was higher in the 276 antibiotic, probiotics, and synbiotics groups, as well as the Asp and TAA contents in 277 the probiotics and synbiotics groups, while the histidine (His) content in the LT muscle 278 was lower in the probiotics group $(P<0.05)$. Moreover, isoleucine (Ile) content in the 279 probiotics and synbiotics groups and lysine (Lys) content in the synbiotics group were 280 higher compared with the control and antibiotic groups, while proline (Pro) content in 281 the synbiotics groups was lower compared with the antibiotic group $(P<0.05)$. At $125-$ 282 day-old, Asp and leucine (Leu) contents in the antibiotic and probiotics groups and the 283 phenylalanine $(\mathrm{Phe})$ content in the synbiotics group were higher $(P<0.05)$ in the LT 
muscle compared with the control group. Moreover, serine (Ser) and His contents in

285 the LT muscle were higher $(P<0.05)$ in the synbiotics group compared with the other

286 three groups at 125-day-old.

\section{Fatty acid contents of longissimus thoracis muscle}

288 The effects of dietary probiotics and synbiotics addition in sow diets during pregnancy

289 and lactation on amino acid contents in the LT muscle of offspring pigs are shown in

290 Table 5. At 65-day-old, compared with the control group, the contents of C18:2n6c and

291 PUFA in the antibiotic and probiotics groups and the contents of C10:0, C12:0, and

292 C14:0 in the synbiotics group were increased $(P<0.05)$ in the LT muscle of pigs,

293 whereas the contents of C16:0 and C20:1 in the probiotics group were decreased $(P<$

294 0.05) in the muscle of pigs. In addition, the content of C24:0 was increased $(P<0.05)$

295 in the probiotics group, while the contents of C18:1n9c, C20:0, and SFA in the

296 probiotics group were decreased $(P<0.05)$ compared with the other three groups.

297 Moreover, the content of $\mathrm{C} 10: 0$ was increased $(P<0.05)$ in the synbiotics group

298 compared with the other three groups, and the content of IMF was decreased $(P<0.05)$

299 in the probiotics group compared with the antibiotic and synbiotics groups. At 95-day-

300 old, the content of C10:0 in the probiotics and synbiotics groups and the content of

301 C14:0 in the probiotic group were increased $(P<0.05)$ in the LT muscle of pigs, while

302 the content of $\mathrm{C} 20: 1$ in the antibiotic and synbiotics groups was decreased $(P<0.05)$

303 compared with the control group. In addition, the content of C12:0 was increased while

304 the content of C16:1 was decreased in the antibiotic, probiotics, and synbiotics groups 
compared with the control group $(P<0.05)$. Moreover, the contents of UFA and MUFA

306 were increased $(P<0.05)$ in the probiotics group compared with the other three groups

307 at 95-day-old. At 125-day-old, the contents of C15:0 in the probiotics and synbiotics

308 groups, $\mathrm{C} 17: 0$ in the probiotics group, $\mathrm{C} 18: 2 \mathrm{n} 6 \mathrm{c}$ in the synbiotics group, and $\mathrm{C} 18: 1 \mathrm{n} 9 \mathrm{t}$

309 in the antibiotic, probiotics, and synbiotics groups were decreased in the LT muscle of

310 pigs compared with the control group. In addition, the contents of C16:1 in the

311 probiotics group and IMF in the synbiotics group were increased $(P<0.05)$ compared

312 with the other three groups.

313 The mRNA expression of myosin heavy chain isoforms, myogenic regulatory

314 factors, and lipid metabolism related genes in longissimus thoracis muscle

315 The effects of probiotics and synbiotics addition in sow diets on mRNA expression of

316 MyHC isoforms, MRFs, and lipid metabolism related genes in the LT muscle of

317 offspring pigs at 65-, 95-, and 125-days are shown in Figure 1. Compared with the

318 control group, the mRNA expression of MyHC IIa in in the antibiotic, probiotics, and

319 synbiotics groups was up-regulated $(P<0.05)$, while the mRNA expressions of $M y H C$

$320 I I x$ and $M y H C I I b$ in the probiotics group were down-regulated $(P<0.05)$ in the LT

321 muscle of pigs at 65-day old (Figure 1 A-B). Moreover, the mRNA expression of

322 MyHC I was up-regulated $(P<0.05)$ in the probiotics group compared with the other

323 three groups and the mRNA expression of Myf6 was down-regulated $(P<0.05)$ in the

324 antibiotic group compared with the probiotics group at 65-day-old (Figure 1 A-B). At

325 95-day-old, the mRNA expression of $M y H C$ IIb and Myf5 in the LT muscle were up- 
regulated $(P<0.05)$ in the probiotics and synbiotics groups compared with the control

327 and antibiotics groups. The mRNA expression of MyHC I and Myf6 in the LT muscle

328 were up-regulated $(P<0.05)$ in the synbiotics group, while the expression of MSTN

329 was down-regulated $(P<0.05)$ when compared with the other three groups (Figure 1

330 A-B). At 125-day-old, the mRNA expression of Myf6 in the antibiotic, probiotics, and

331 synbiotics groups and the mRNA expression of MyHC IIa in the antibiotic and

332 synbiotics groups were up-regulated $(P<0.05)$ in the LT muscle compared with the

333 control group. In addition, the mRNA expression of $M y O G$ in the probiotics and

334 synbiotics groups was down-regulated $(P<0.05)$ compared with the control and

335 antibiotics groups. Moreover, the mRNA expression of MyHC I and Myf5 were up-

336 regulated $(P<0.05)$ in the antibiotic group compared with the control and probiotics

337 groups (Figure $\mathbf{1}$ A-B).

338 As shown in Figure 1 C-D, at 65-day-old, the mRNA expression of stearoyl-CoA

339 desaturase $(S C D)$ in the LT muscle was down-regulated $(P<0.05)$ in the antibiotic,

340 probiotics, and synbiotics groups compared with the control group, whereas the mRNA

341 expression of lipoprotein lipase $(L P L)$ was up-regulated $(P<0.05)$ in the probiotics

342 group compared with the other three groups. At 95-day-old, the mRNA expression of

$343 L P L$ in the antibiotic, probiotics, and synbiotics groups and the mRNA expression of

344 acetyl-CoA carboxylase $(A C C)$ in the probiotics group were up-regulated $(P<0.05)$

345 compared with the control group. Moreover, the mRNA expression of fatty acid

346 synthase $(F A S N)$ in the probiotics and synbiotics groups and the mRNA expression of 
$347 S C D$ in the synbiotics group were up-regulated $(P<0.05)$, compared with the control

348 and antibiotic groups. At 125-day-old, the mRNA expression of $L P L$ was up-regulated

$349(P<0.05)$ in the antibiotic, probiotics, and synbiotics groups compared with the control

350 group. The mRNA expression of $A C C$ was up-regulated in the antibiotic and synbiotics

351 groups and down-regulated in the probiotics group compared with the control group.

352 Moreover, the mRNA expressions of $F A S N$ and $S C D$ were up-regulated $(P<0.05)$ in

353 the antibiotic group compared with the other three groups, while the mRNA expression

354 of hormone-sensitive triglyceride lipase (LIPE) was down-regulated compared with the

355 control group.

\section{Plasma biochemical parameters}

357 To evaluate the effects of maternal probiotics or synbiotics addition in sows' diets on

358 offspring pigs, we measured the plasma biochemical parameters at 65-, 95-, and 125-

359 day-old, and the results are presented in Table 6. At 65-day-old, compared with the

360 control group, the plasma activity of $\alpha$-AMS in the antibiotic, probiotics, and synbiotics

361 groups, while the plasma activity of LDH was increased in the antibiotic group and

362 decreased in the probiotic group $(P<0.05)$. The concentrations of LDL-C and TC were

363 increased in the antibiotic group while decreased in the synbiotics group compared with

364 the control group $(P<0.05)$. In the synbiotics group, the concentration of HDL-C was

365 increased compared with the other three groups, while the concentration of Glu was

366 decreased compared with the control and probiotics groups $(P<0.05)$. Moreover, the

367 concentrations of ALB in the antibiotic group and CHE in the probiotics group were 
368 decreased $(P<0.05)$ compared with the other three groups. At 95-day-old, the plasma

369 activities of AST and LDH in the antibiotic and probiotics groups, the concentration of

370 GLU in the antibiotic, probiotics, and synbiotics groups, and concentration of TG in the

371 synbiotics group were decreased $(P<0.05)$ compared with the control group.

372 Compared with the control and antibiotic groups, the plasma CHE activity and UN

373 concentration were decreased $(P<0.05)$ in the probiotics and synbiotics groups.

374 Moreover, the plasma concentration of AMM was decreased $(P<0.05)$ in the probiotics

375 group compared with the other three groups. At 125-day-old, the plasma concentration

376 of HDL-C was increased $(P<0.05)$, whereas the AST and LDH activities were

377 decreased $(P<0.05)$ in the antibiotic and probiotics groups compared with the control

378 group. The plasma concentration of AMM was decreased $(P<0.05)$ in the antibiotic,

379 probiotics, and synbiotics groups, while the plasma activity of $\alpha$-AMS was increased

$380(P<0.05)$ in the antibiotic and synbiotics groups, when compared with the control

381 group. Moreover, the plasma concentration of TP in the antibiotic group was decreased

$382(P<0.05)$, and the plasma concentration of TG in the synbiotics group was increased

$383(P<0.03)$ compared with the other three groups.

384 Plasma free amino acid concentration

385 Table 7 presents the effects of maternal probiotics or synbiotics addition in sow's diets 386 in offspring pigs' plasma free amino acid concentration. At 65-day-old, the plasma 387 histidine (His) concentration in the probiotics group, the hydroxy-proline (Hypro) 388 concentration in the antibiotic, probiotics, and synbiotics groups, and the $\beta$ - 
aminoisobutyric acid ( $\beta$-AiBA) concentration in the antibiotic and synbiotics groups were increased $(P<0.05)$, whereas the plasma Gly, Ile, sarcosine $($ Sar $)$, and taurine

391 (Tau) concentrations in the antibiotic and probiotics groups and the Leu concentration 392 in the probiotics group were decreased $(P<0.05)$, compared with the control group. 393 Compared with the control and antibiotic groups, the plasma citrulline (Cit) and 394 cystathionine (Cysthi) concentrations were increased $(P<0.05)$ in the synbiotics group, 395 while the plasma alanine (Ala) concentration was decreased $(P<0.05)$ in the probiotics 396 group. The plasma $\gamma$-amino-n-butyric acid $(\gamma$-ABA) concentration was increased in the 397 synbiotics group compared with the other three groups, while the plasma tyrosine (Tyr) 398 concentration was decreased and the plasma hydroxy-lysine (Hylys) was increased in 399 the probiotics group compared with the other three groups $(P<0.05)$. However, the 400 antibiotic group had increased $(P<0.05)$ plasma threonine $(\mathrm{Thr})$ and Pro concentrations 401 compared with the other three groups.

$403 \beta$-alanine ( $\beta$-Ala), and $\gamma$-ABA concentrations were decreased, and the plasma $\gamma$-amino404 n-butyric acid ( $\beta$-AiBA) was increased in the antibiotic, probiotics, and synbiotics 405 groups, compared with the control group $(P<0.05)$. In addition, compared with the 406 control group, the plasma $\beta$-AiBA concentration was increased, and the ethanolamine 407 (EOHNH2) concentration was decreased in the probiotics and synbiotics groups $(P<$ 408 0.05). Compared with the control and antibiotic groups, the plasma Sar concentration 409 was increased, and the EOHNH2 was decreased in the probiotics and synbiotics groups, 

as well the plasma Cysthi concentration was increased in the synbiotics group $(P<$

411 0.05). Moreover, the plasma Hylys concentration was increased, and the plasma 412 anserine (Ans) concentration was decreased in the synbiotics groups, compared with 413 the other three groups. However, the antibiotic group had increased $(P<0.05)$ plasma 414 1-Methyl-histidine (1-Mehis), EOHNH2, and ornithine (Orn) concentrations compared 415 with the other three groups. At 125-day-old, the plasma Ans and methionine (Met) concentrations in the 417 antibiotic and probiotics groups, the plasma valine (Val) and Leu concentrations in the 418 antibiotic and synbiotics groups were increased, compared with the control group. The 419 plasma $\alpha$-ABA concentration was increased, whereas the Orn concentration was 420 decreased in the antibiotic, probiotics, and synbiotics groups compared with the control 421 group $(P<0.05)$. Compared with control and antibiotic groups, the plasma Cysthi 422 concentration was increased in the synbiotics group, while the plasma Ser concentration 423 was decreased in the probiotics and synbiotics groups $(P<0.05)$. Moreover, the plasma 424 Asp and His concentrations were increased in the probiotics group, and the plasma 425 EOHNH2 concentration was decreased in the synbiotics group, when compared with 426 the other three groups $(P<0.05)$. However, the antibiotic group had increased $(P<$ 427 0.05) plasma Thr, Ala, Arg, Gly, Pro, Ser, Tau, Tyr, and $\beta$-AiBA concentrations 428 compared with the other three groups.

\section{Discussion}


430 There is growing scientific and industrial interest for prebiotics, probiotics, and 431 synbiotics addition in pig production [21, 22]. Numerous studies showed that dietary 432 probiotics or synbiotics could improve the health status and production performance of 433 pigs by modulating intestinal microbiota $[23,24]$. Therefore, the present study aimed 434 to determine the effects of maternal gut microbiota intervention via dietary probiotics 435 or synbiotics addition on the growth performance, carcass traits, meat quality, and 436 metabolites of their offspring pigs. Our findings indicated that dietary probiotics or 437 synbiotics addition in Bama mini-pigs' diets could improve growth performance, meat 438 quality, and the body's metabolism of offspring pigs.

439 Dietary probiotics or synbiotics addition in diets have been widely used in 440 livestock production. Recent studies have found that can improve the growth 441 performance in growing-finishing pigs [25], such as dietary Lactobacillus plantarum 442 ZLP001 addition could increase the ADFI of weaning piglets [26]. In the present study, 443 maternal probiotics or synbiotics addition did not affect the growth performance of 444 offspring pigs, except for an increase of ADFI in the probiotics group during the 66-95 445 day-old. A possible reason for the inconsistent growth performance of the present study 446 might be related to the pig breeds. Moreover, Bergamaschi et al. (2020) demonstrated 447 that three breed pigs present different ADFI due to their different gut microbiota 448 composition [27]. Our previous study also showed that dietary synbiotics (including 449 Lactobacillus plantarum $\geq 1.0 \times 10^{8} \mathrm{CFU} / \mathrm{g}$, Saccharomyces cerevisiae $\geq 0.2 \times 10^{8}$ $450 \mathrm{CFU} / \mathrm{g}$ and XOS) addition can alter the abundance, diversity, and composition of gut 
451 microbiota in pregnant and lactating sows [10]. However, the present study also found

452 that maternal antibiotic addition significantly decreased the ADFI of offspring pigs

453 during 66-95 day-old and increased F/G during 96-125 day-old, which may be related

454 to the adverse effects of antibiotic use during pregnancy on the offspring [28]. A

455 previous study also indicated that maternal antibiotic addition could alter the maternal

456 and fetus microbiome in utero and during the postnatal period through maternal-fetus

457 interaction, thereby affecting the health of offspring [29]. Therefore, the adverse effect

458 of maternal antibiotic addition on the growth performance of offspring needs to be

459 further studied.

460 Carcass traits and meat quality are the major factors that influence the meat flavor,

461 tenderness, juiciness, and overall consumer acceptance. In the present study, maternal

462 probiotics or synbiotics addition increased the backfat thickness and fat percentage of

463 offspring pigs at 125-day-old along with the antibiotic, while probiotics addition

464 increased backfat thickness at 65-day-old, suggesting that these additives could

465 improve body fat deposition and then improve the meat tenderness in the 125-day-old

466 pigs. Generally, the loin-eye area is positively related to the lean meat rate and

467 negatively related to backfat thickness. However, the present study showed a decrease

468 in the loin-eye area and lean meat rate in the synbiotics group at 125-day-old, indicating

469 that maternal synbiotics has no impact on lean meat. Previous studies also found that

470 dietary XOS addition has no significant effect on lean meat [30, 31]. This inconsistency 
may be correlated with the pig breed. Bama mini-pig belongs to the fatty breed of pigs, which has higher fat content than the Landrace pigs [19].

Meat color is an important sensory index because it affects consumers' first impression of the meat, and it is generally evaluated by redness, lightness, and yellowness values [32]. The high-quality meat has higher redness values and lower lightness and yellowness values [33]. In the present study, maternal synbiotics addition increased the redness values at 95-day-old and decreased the lightness values at 125day-old in the LT muscle of offspring pigs. Moreover, maternal probiotics decreased the lightness and redness values of LT muscle at 65- and 95-day-old, respectively. Previous studies have reported that dietary synbiotics (including yeast cell wall, XOS, Clostridium butyricum, Bacillus licheniformis, and Bacillus subtilis) had no effects on the redness and lightness values [34], while dietary probiotics addition could increase the redness values but not lightness values [32]. However, the present study suggesting that maternal synbiotics addition could improve the sense-impression of pork, while probiotics addition has no positive effect on meat color. These inconsistent findings might be related to the feeding stage and the type and dose of probiotics or synbiotics. Additionally, the results of this study revealed that maternal probiotics or synbiotics addition also improved the meat quality by increasing $\mathrm{pH}$, water holding capacity, and cooking yield and decreasing the shear force in the LT muscle of offspring pigs. After slaughter, due to glycolysis, the accumulation of lactic acid in the muscle leads to a decrease in $\mathrm{pH}$, which is highly correlated with the drip loss and shear force 
492 [35]. Drip loss can reflect the water-holding capacity of muscle and is also an important

493 factor affecting meat quality [36], while shear force is correlated with meat tenderness

494 (50). In the present study, maternal probiotics addition increased $\mathrm{pH} 45 \min$ at 95-day-old

495 and cooking yield at 65-day-old, while maternal probiotics or synbiotics addition

496 increased water holding capacity at 65-day-old and decreased shear force at 125-day-

497 old. However, maternal antibiotic addition showed an increased shear force of the LT

498 muscle at 125-day-old. A previous study reported that drip loss usually ranges from $2 \%$

499 to $10 \%$ when the meat is cut into slices [37], which is consistent with the present study

500 (ranges $2.78 \%-6.32 \%$ ). The results were also consistent with the previous studies by

501 Suo et al. (2012), who demonstrated that Lactobacillus plantarum ZJ316 addition

502 improved $\mathrm{pH}_{45 \min }$ [38], and Zhou et al. (2010), who reported that Bacillus coagulans

503 could affect meat quality by decreasing drip loss [39]. Thus, the results of the present

504 study indicated that maternal probiotics addition could decrease the lactic acid

505 accumulation by improving muscle glycolysis, while maternal probiotics or synbiotics

506 addition could increase water holding capacity and cooking by reducing drip loss,

507 cooking loss, and shear force and thereby improve meat quality.

508 Changes in the nutrient contents of muscular tissue, especially the contents of IMF

509 and CP, could directly affect the sensory properties and nutritional values of meat [40].

510 Moreover, the IMF is a major quality trait of meat, of which content influences the

511 consumers' perceptions of cooked pork palatability [41]. Fernandez et al. (1999)

512 demonstrated that the tenderness, juiciness, color, and flavor of meat were substantially 
513 improved with the increase in IMF content[42]. In the present study, maternal

514 synbiotics addition increased the IMF content of LT muscle at 125-day-old, indicating

515 that the meat quality was improved by maternal synbiotics addition. The change in IMF

516 content of LT muscle is consistent with the change of shear force in LT muscle because

517 the IMF content has a negative correlation with the shear force [43]. Moreover, the

518 higher IMF content can improve the taste of meat [44].

519 Amino acids play pivotal roles in the growth, development, reproduction, and

520 health of animals. Moreover, the composition and contents of amino acids in muscle

521 could represent the protein quality and nutritional value of meat [45]. In the present

522 study, dietary probiotic or synbiotics addition significantly increased the TAA contents

523 in the LT muscle at 95-day-old, suggesting that the nutritional value of pork of growing

524 pigs was improved by increasing amino acid deposition. Several AA play key roles in

525 the aroma and flavor profiles of muscle [46]. For example, Arg, Leu, Ile, Val, Phe, Met,

526 and His present a bitter taste; Glu and Asp present a pleasant fresh taste; and Gly, Ala,

527 and Ser present a sweet taste [47]. In the present study, maternal probiotics or synbiotics

528 addition increased several AA contents, including His, Arg, Asp, Leu, Ser, and Phe, at

529 different stages in the LT muscle. These changes could improve the flavor of LT muscle

530 of offspring pigs. A previous study also indicated that dietary Clostridium butyricum

531 addition improved the flavor of the duck meat through altering FAA content [48]. Free

532 AA are the main direct source of amino acids for muscle protein synthesis and the key

533 index of protein renewal [49]. Plasma free AA profile reflects the sum of metabolic 
534 flow of nutrients and their metabolites from all tissues and organs [50]. Plasma free AA

535 profile also reflects the dynamics state of the metabolic flux of AAs absorbed from the

536 small intestine, as well as the rates of their utilization and intracellular protein turnover

537 in the whole body [51]. For example, Gly has crucial roles in nutrition and metabolism,

538 and protein synthesis accounts for $80 \%$ of whole-body glycine needs by growing

539 animals [52]. Branched-chain AA, including Leu, Ile, and Val, have an impact on the

540 regulation of energy homeostasis and nutrition metabolism [53]. Our results showed

541 that plasma Gly, Ile, Leu, and Tau concentrations were decreased in the probiotics or

542 synbiotics groups at 65- or 125-day-old, suggesting that maternal probiotics or

543 synbiotics addition attenuates the breakdown of protein in muscle and then promotes

544 the AA deposition in the muscle. In addition, the present study also showed that

545 maternal probiotics addition decreased the plasma Asp, Ala, Sar, Tyr, Car, and His

546 concentrations, while probiotics or synbiotics addition decreased the plasma Orn, Cit,

$547 \alpha$-AAA, $\alpha$-ABA, $\beta$-Ala, and $\gamma$-ABA concentrations at different stages of age, suggesting

548 that maternal probiotics and synbiotics addition could improve the protein synthesis of

549 the body.

550 Plasma biochemical parameters reflect the physiological and nutritional status of

551 the animal [54]. The ALT and AST activities can reflect the status of protein synthesis

552 and catabolism, and the increased activities were related to the improvement of amino

553 acid metabolism [55]. The AMM and UN concentrations accurately reflect the status

554 of protein metabolism and AA balance. The present study showed that maternal 
556 concentrations at different stages. These results indicated that maternal probiotics or

557 synbiotics addition could promote the balance of AA and improve the utilization of

558 protein and then the deposition of protein. The rate of lipid utilization could be reflected

559 by the TC, TG, HDL-C, and LDL-C [56]. In the present study, maternal synbiotics

560 addition increased HDL-C, LDL-C, and TC concentrations at 65-day-old and decreased

561 TG concentration at 95-day-old. However, maternal antibiotic addition decreased the

562 concentrations of LDL-C and TC at 65-day-old. These findings suggested that maternal

563 synbiotics improved the lipid metabolism of offspring pigs, while maternal antibiotic

564 addition had a negative effect on the lipid metabolism. The plasma levels of LDH and

565 GLU can reflect energy and glucose metabolism, respectively. The present study

566 showed that LDH activity was decreased in the probiotics group at 95- and 125-day-

567 old, GLU concentration was decreased in the synbiotics group at 65-day-old, and in the

568 probiotics and synbiotics group at 95-day-old. Therefore, the results indicated that

569 maternal probiotics addition improved the energy and glucose metabolism of offspring

570 pigs, while maternal synbiotics addition improved glucose metabolism.

571 The FA composition profoundly affects the nutritional value, organoleptic

572 properties, and eating quality of pork [57, 58]. The C14:0, C16:0, C16:1n7, C18:0,

$573 \mathrm{C} 18: 1 \mathrm{n} 9$, and $\mathrm{C} 18: 2 \mathrm{n} 6$ are the primary FA in pork [59]. In the present study, maternal

574 probiotics addition increased the C18:2n6c, MUFA, and UFA contents in the LT

575 muscle at different stages. Similarly, previous studies also found that dietary probiotics, 
577 profiles of pork by enhancing the contents of C18:2n6c, MUFA, and PUFA [60]. These

578 alterations indicated that maternal probiotics could improve the primary FA in the 579 muscle of offspring pigs, which may be associated with the favorable changes in the 580 gut microbiota after probiotics addition [61]. The FA profiles of pork can be improved 581 by increasing UFA and decreasing SFA contents in the muscle [60]. Moreover, meat 582 with lower SFA contents could reduce the risk of cardiovascular heart diseases [62]. In 583 the present study, maternal probiotics addition decreased the SFA content at 65-day584 old, suggesting that the nutritional value of meat was improved by maternal probiotics 585 addition. Cameron et al. (2000) indicated that the C16:1 content was positively 586 correlated with meat flavor [63]. In our study, maternal probiotics or synbiotics addition 587 increased the $\mathrm{C} 16: 1$ content at 95-day-old, suggesting that these additives could improve 588 the pork flavor of offspring pigs. In addition, maternal probiotics or synbiotics addition 589 decreased the C18:1n9t content at 125-day-old, which is a kind of trans FA and has 590 adverse effects on human health [64]. Consequently, maternal probiotics or synbiotics 591 addition could improve the meat quality and nutritional value of offspring pigs, which 592 would have beneficial effects on human health.

593 The muscle fiber type is mainly defined by the myosin heavy chain (MyHC) 594 isoforms [65], and the fiber type composition is largely responsible for the 595 determination of meat quality [66]. The higher proportion of $M y H C I$ and $M y H C$ IIa 596 fibers are related to the excellent meat quality [67]. In the present study, the expressions 

different stages. In addition, the expressions of $M y H C$ IIb and $M y H C$ IIx were downregulated in the synbiotics group at 65-day-old. The MRF gene family, including MyoD, $M y o G, M y f 5$, and Myf6, plays dominant roles in muscle fiber formation, muscle 601 maturation, and functional perfection of muscle fibers [68]. Myostatin (MSTN), a 602 negative regulator of myogenesis, can inhibit muscle growth and development [69].

603 Previous studies indicated that the expression of the MRF gene family affected the 604 expression of MyHC gene isoforms [70], and the MSTN plays an important role in the 605 muscle fiber-type conversion [71]. In the present study, maternal probiotics and 606 synbiotics addition up-regulated the Myf5 and Myf6 mRNA levels at 95- and 125-day607 old, respectively; whereas synbiotics down-regulated the MSTN mRNA level at 95-day608 old. Therefore, these findings indicated that maternal probiotics or synbiotics addition 609 had positive effects on enhancing muscle growth and altering muscle fiber type 610 composition.

611 Lipogenesis and lipolysis are major factors affecting fat accumulation in adipose 612 tissue and animal products. The FASN and ACC could modulate fat deposition in 613 animals by regulating FA synthesis [19]. The $S C D$ is involved in the FA biosynthesis 614 and composition [72]. In the present study, maternal probiotics or synbiotics addition 615 up-regulated the $A C C, S C D$, and $F A S N$ mRNA levels at different age stages of offspring 616 pigs. These findings suggested that maternal probiotics or synbiotics addition improved 617 the fat deposition and FA composition in the LT muscle of offspring pigs. The $L P L$, the 
618 critical lipid uptake gene, encodes a protein that participates in the process of fatty acid

619 flux into adipocytes clustered along myofiber fasciculi in the muscle and then provides

620 the appropriate substrate for IMF synthesis [73]. A previous study also indicated that

621 the expressions of FASN, SCD, and $L P L$ have a positive association with the IMF

622 deposition [74]. In the present study, the beneficial effect of maternal probiotics or

623 synbiotics addition on the deposition of IMF could be elucidated by the up-regulation

624 of $L P L$ mRNA expression level at 95- and 125-day-old. This finding was also consistent

625 with the increased IMF content of the LT muscle in the present study. Moreover, the

$626 L I P E$ was found to participate in the lipolysis and negatively correlated with the IMF

627 deposition [74]. Our results also showed that maternal antibiotic addition not only up-

628 regulated the expression levels of FASN, $L P L, S C D$, and $A C C$, but also up-regulated

$629 L I P E$ expression at 125-day-old. Thus, indicating that antibiotic addition does not have

630 the positive effects on the lipid metabolism of LT muscle.

631 Conclusions

632 In summary, maternal synbiotics addition showed only the improvement in daily feed

633 intake, while maternal antibiotics addition had adverse effects on the growth

634 performance of offspring pigs. Dietary probiotics or synbiotics addition during

635 pregnancy and lactation could improve offspring piglets' body metabolism by

636 promoting glucose, amino acids, and energy metabolism. Furthermore, maternal

637 probiotics or synbiotics addition could increase meat quality and nutritional value of

638 meat, including the increase of fat or protein deposition, the improvement of sensory 
639 impression, and the alteration of amino acids and fatty acids profiles, by improving the

640 composition of muscle fiber type and growth, and lipid metabolism. However, maternal

641 antibiotic addition had no effects on the lipid metabolism of LT muscles of offspring

642 pigs. Collectively, maternal probiotics or synbiotics could serve as a maternal

643 nutritional intervention strategy to improve feed intake, the body's metabolism, and

644 meat quality of offspring pigs, which are better than the antibiotic.

\section{Abbreviations}

646 1-Mehis, 1-methyl-histidine; 3-Mehis, 3-methyl-histidine; ACC, acetyl-CoA 647 carboxylase; ADG, average daily gain; ADFI, average daily feed intake; Ala, alanine;

648 ALT, alanine aminotransferase; ALP, alkaline phosphatase; ALB, albumin; AMM, 649 ammonia; Ans, anserine; Arg, arginine; Asp, aspartate; AST, aspartate 650 aminotransferase; BW, body weight; Car, carnosine; CHE, cholinesterase; Cit, 651 citrulline; Cysthi, cystathionine; Cys, cysteine; CP, crude protein; DM, dry matter; 652 EOHNH2, ethanolamine; EAA, essential amino acids; FAA, flavor amino acids; FA, 653 fatty acids; F/G, feed/gain ratio; FASN, fatty acid synthase; Glu, glutamate; GLU, 654 glucose; Gly, glycine; HDL-C, high density lipoprotein-cholesterol; His, histidine; 655 Hylys, hydroxy-lysine; Hypro, hydroxy-proline; IMF, intramuscular fat; Ile, isoleucine; 656 LDH, lactate dehydrogenase; LDL-C, low density lipoprotein-cholesterol; Leu, leucine; 657 LIPE, hormone-sensitive triglyceride lipase; LT, longissimus thoracis; $L P L$, lipoprotein 658 lipase; Lys, lysine; Met, methionine; MRFs, myogenic regulatory factors; MUFA, 659 monounsaturated fatty acid; Myf5, myogenic factor 5; Myf6, myogenic factor 6; MyHC, 
660

661 acids; Orn, ornithine; Phe, phenylalanine; Pro, proline; PUFA, polyunsaturated fatty

662 acids; Sar, sarcosine; $S C D$, stearoyl-CoA desaturase; Ser, serine; SFA, saturated fatty

663 acid; $S R E B P-1$, sterol-regulatory element-binding protein-1; TAA, total amino acids;

664 Tau, taurine; TC, total cholesterol; TG, triglyceride; Thr, threonine; TP, total protein;

665 Tyr, tyrosine; UFA, unsaturated fatty acid; UN, urea nitrogen; Val, valine; XOS, xylo-

666 oligosaccharides; $\alpha$-AAA, $\alpha$-aminoadipic acid; $\alpha$-ABA, $\alpha$-amino-n-butyric acid; $\alpha$ -

667 AMS, $\alpha$-amylase; $\beta$-Ala, $\beta$-alanine; $\beta$-AiBA, $\beta$-aminoisobutyric acid; and $\gamma$-ABA, $\gamma$ -

668 amino-n-butyric acid.

\section{Authors' contributions}

$670 \mathrm{XK}$ and YY conceived and design the experiment and revised the manuscript. QZ, MS,

671 MA, and CM performed the animal feeding experiment, sample collection, and sample

672 analysis. QZ analyzed the data and wrote the manuscript. All the authors read and

673 approved the final manuscript.

\section{Funding}

675 The present work was jointly supported by the National Natural Science Foundation of

676 China (31772613), Special Funds for Construction of Innovative Provinces in Hunan

677 Province (2019RS3022), and Industry and Research Talent Support Project from Wang

678 Kuancheng of the Chinese Academy of Sciences.

\section{Acknowledgments}


680 We thank all staff and postgraduate students of Hunan Provincial Key Laboratory of

681 Animal Nutritional Physiology and Metabolic Process for animal feeding and sample

682 collection, and technicians from CAS Key Laboratory of Agro-ecological Processes in

683 Subtropical Region for providing technical assistance.

684 Declarations

685 Ethics approval and consent to participate

686 The animal procedures in the present study followed the Chinese Guidelines for Animal

687 Welfare and experimental protocols approved by the Animal Care and Use Committee

688 of the Institute of Subtropical Agriculture, Chinese Academy of Science.

689 Consent for publication

690 Not applicable.

691 Competing interests

692 The authors declared that no conflict of interest.

693 References

694 1. Prakash S, Rodes L, Coussa-Charley M, Tomaro-Duchesneau C. Gut microbiota: 695 next frontier in understanding human health and development of biotherapeutics. 696 Biologics. 2011;5:71-86. https://doi.org/10.2147/BTT.S19099.

697 2. Schrezenmeir J, de Vrese M. Probiotics, prebiotics, and synbiotics--approaching a 698 definition. Am J Clin Nutr. 2001;73(2):361S-4S. 699 https://doi.org/10.1093/ajcn/73.2.361s.

700 3. Baker AA, Davis E, Spencer JD, Moser R, Rehberger T. The effect of a Bacillus701 based direct-fed microbial supplemented to sows on the gastrointestinal microbiota 702 of their neonatal piglets. J Anim Sci. 2013;91(7):3390-9. 703 https://doi.org/10.2527/jas.2012-5821. 
4. Yin J, Li FN, Kong XF, Wen CY, Guo QP, Zhang LY, et al. Dietary xylooligosaccharide improves intestinal functions in weaned piglets. Food Funct. 2019;10(5):2701-9. https://doi.org/10.1039/c8fo02485e.

5. Oksbjerg N, Krogh U, Jensen JA, Møller HS, Ramaekers P, Rasmussen MK, et al. Supplementation of sows with -arginine during gestating and lactation affects muscle traits of offspring related with postnatal growth and meat quality: From conception to consumption. Meat Sci. 2019;152:58-64. https://doi.org/10.1016/j.meatsci.2019.02.004.

6. Zhao Y, Jin C, Xuan Y, Zhou P, Fang Z, Che L, et al. Effect of maternal or postweaning methyl donor supplementation on growth performance, carcass traits, and meat quality of pig offspring. J Sci Food Agric. 2019;99(5):2096-107. https://doi.org/10.1002/jsfa.9402.

7. Stickland NC, Handel SE. The numbers and types of muscle fibres in large and small breeds of pigs. J. Anat. 1986;147:181-9.

8. Du M, Zhao JX, Yan X, Huang Y, Nicodemus LV, Yue W, et al. Fetal muscle development, mesenchymal multipotent cell differentiation, and associated signaling pathways. J Anim Sci. 2011;89(2):583-90. https://doi.org/10.2527/jas.2010-3386.

9. Ma C, Gao QK, Zhang WH, Zhu Q, Tang W, Blachier F, et al. Supplementing synbiotic in sows' diets modifies beneficially blood parameters and colonic microbiota composition and metabolic activity in suckling piglets. Front Vet Sci. 2020;7:575685. https://doi.org/10.3389/fvets.2020.575685.

10. Ma C, Zhang WH, Gao QK, Zhu Q, Song MT, Ding H, et al. Dietary synbiotic alters plasma biochemical parameters and fecal microbiota and metabolites in sows. J Funct Food. 2020;75:104221. https://doi.org/10.1016/j.jff.2020.104221.

11. Gong HF, Xiao SJ, Li WB, Huang T, Huang XC, Yan GR, et al. Unravelling the genetic loci for growth and carcass traits in Chinese Bamaxiang pigs based on a 1.4 million SNP array. J Anim Breed Genet. 2019;136(1):3-14. https://doi.org/10.1111/jbg.12365.

12. NPPC. National Pork Producers Council. Procedures to evaluate market hogs $\left(3^{\text {rd }}\right.$ ed.). Des Moines, IA: National Pork Producers Council. 1911.

13. Honikel K. Reference methods for the assessment of physical characteristics of meat. Meat Sci. 1998;49(4):447-57. https://doi.org/10.1016/s0309-1740(98)00034$\underline{5}$.

14. Yu M, Li ZM, Chen WD, Rong T, Wang G, Li JH, et al. Use of Hermetia illucens larvae as a dietary protein source: Effects on growth performance, carcass traits, and meat quality in finishing pigs. Meat Sci. 2019;158:107837. https://doi.org/10.1016/j.meatsci.2019.05.008. 
15. AOAC. P. Cunniff, editor, Official methods of analysis. $16^{\text {th }}$ ed. Assoc. Off. Anal. Chem. Int., Gaithersburg. 1996;

16. Novakofski J, Park S, Bechtel PJ, McKeith FK. Composition of cooked pork chops - effect of removing subcutaneous fat before cooking. J Food Sci. 1989;54(1):15-7. https://doi.org/10.1111/j.1365-2621.1989.tb08556.x.

17. Liu YY, Li FN, Kong XF, Tan B, Li YH, Duan YH, et al. Signaling pathways related to protein synthesis and amino acid concentration in pig skeletal muscles depend on the dietary protein level, genotype and developmental stages. PloS One. 2015;10(9):e0138277. https://doi.org/10.1371/journal.pone.0138277.

18. Kong XF, Yin FG, He QH, Liu HJ, Li TJ, Huang RL, et al. Acanthopanax senticosus extract as a dietary additive enhances the apparent ileal digestibility of amino acids in weaned piglets. Livest Sci. 2009;123(2-3):261-7. https://doi.org/10.1016/j.livsci.2008.11.015.

19. Liu YY, Li FN, He LY, Tan B, Deng JP, Kong XF, et al. Dietary protein intake affects expression of genes for lipid metabolism in porcine skeletal muscle in a genotype-dependent manner. $\mathrm{Br} \quad \mathrm{J}$ Nutr. 2015;113(7):1069-77. https://doi.org/10.1017/s0007114514004310.

20. Schmittgen TD, Livak KJ. Analyzing real-time PCR data by the comparative C(T) method. Nat Protoc. 2008;3(6):1101-8. https://doi.org/10.1038/nprot.2008.73.

21. Guerra-Ordaz AA, González-Ortiz G, La Ragione RM, Woodward MJ, Collins JW, Pérez JF, et al. Lactulose and Lactobacillus plantarum, a potential complementary synbiotic to control postweaning colibacillosis in piglets. Appl Environ Microbiol. 2014;80(16):4879-86. https://doi.org/10.1128/AEM.00770-14.

22. Martinez RCR, Cardarelli HR, Borst W, Albrecht S, Schols H, Gutiérrez OP, et al. Effect of galactooligosaccharides and Bifidobacterium animalis $\mathrm{Bb}-12$ on growth of Lactobacillus amylovorus DSM 16698, microbial community structure, and metabolite production in an in vitro colonic model set up with human or pig microbiota. FEMS Microbiol Ecol. 2013;84(1):110-23. https://doi.org/10.1111/1574-6941.12041.

23. Yang CM, Ferket PR, Hong QH, Zhou J, Cao GT, Zhou L, et al. Effect of chitooligosaccharide on growth performance, intestinal barrier function, intestinal morphology and cecal microflora in weaned pigs. J Anim Sci. 2012;90(8):2671-6. https://doi.org/10.2527/jas.2011-4699.

24. Markowiak P, Śliżewska K. The role of probiotics, prebiotics and synbiotics in animal nutrition. Gut Pathog. 2018;10(1):21. https://doi.org/10.1186/s13099-018$\underline{0250-0 .}$.

25. Tufarelli V, Crovace AM, Rossi G, Laudadio V. Effect of a dietary probiotic blend on performance, blood characteristics, meat quality and faecal microbial shedding 
in growing-finishing pigs. $\mathrm{S}$ Afr $\mathrm{J}$ Anim Sci. 2017;47(6):875-82. https://doi.org/10.4314/sajas.v47i6.15.

26. Wang J, Ji HF, Wang SX, Zhang DY, Liu H, Shan DC, et al. Lactobacillus plantarum ZLP001: In vitro assessment of antioxidant capacity and effect on growth performance and antioxidant status in weaning piglets. Asian-Australas J Anim Sci. 2012;25(8):1153-8. https://doi.org/10.5713/ajas.2012.12079.

27. Bergamaschi M, Tiezzi F, Howard J, Huang YJ, Gray KA, Schillebeeckx C, et al. Gut microbiome composition differences among breeds impact feed efficiency in swine. Microbiome. 2020;8(1):110. https://doi.org/10.1186/s40168-020-00888-9.

28. Amir M, Brown JA, Rager SL, Sanidad KZ, Ananthanarayanan A, Zeng MY. Maternal microbiome and infections in pregnancy. Microorganisms. 2020;8(12):1996. https://doi.org/10.3390/microorganisms8121996.

29. Lemas DJ, Yee S, Cacho N, Miller D, Cardel M, Gurka M, et al. Exploring the contribution of maternal antibiotics and breastfeeding to development of the infant microbiome and pediatric obesity. Semin Fetal Neonatal Med. 2016;21(6):406-9. https://doi.org/10.1016/j.siny.2016.04.013.

30. Pan J, Han L, Zhang T, Xie PF, Ding H, Kong XF, et al. Effects of xylooligosaccharide on growth performance, carcass traits and meat quality in growingfinishing pigs. Chin J Anim Nutr. 2017;29(7):2475-81. https://doi.org/10.3969/j.issn.1006-267x.2017.07.032.

31. Xing TJ, Han L, Xie PF, Kong XF, Ding H, Fang RJ. Effects of dietary supplementation with xylo-oligosaccharide on plasma biochemical parameters and meat quality in finishing pigs. Chin J Anim Nutr. 2018;54(9):94-9. https://doi.org/doi:10.19556/j.0258-7033.2018-09-094.

32. Meng QW, Yan L, Ao X, Zhou TX, Wang JP, Lee JH, et al. Influence of probiotics in different energy and nutrient density diets on growth performance, nutrient digestibility, meat quality, and blood characteristics in growing-finishing pigs. $\mathrm{J}$ Anim Sci. 2010;88(10):3320-6. https://doi.org/10.2527/jas.2009-2308.

33. Martins JM, Fialho R, Albuquerque A, Neves J, Freitas A, Nunes JT, et al. Growth, blood, carcass and meat quality traits from local pig breeds and their crosses. Animal. 2020;14(3):636-47. https://doi.org/10.1017/s1751731119002222.

34. Cheng YF, Chen YP, Du MF, Wen C, Zhou YM. Evaluation of dietary synbiotic supplementation on growth performance, muscle antioxidant ability and mineral accumulations, and meat quality in late-finishing pigs. Kafkas Univ Vet Fak Derg. 2018;24(5):673-9. https://doi.org/10.9775/kvfd.2018.19713.

35. Jiang SW, Liu YS, Shen ZL, Zhou B, Shen QW. Acetylome profiling reveals extensive involvement of lysine acetylation in the conversion of muscle to meat. $\mathrm{J}$ Proteomics. 2019;205:103412. https://doi.org/10.1016/j.jprot.2019.103412. 
36. Liu X, Kim SH, Kim IH. Effects of the combination of multistrain probiotics and Castanea crenata shell extract on growth performance, nutrient digestibility, fecal microbial shedding, meat quality, noxious gas emissions, and blood parameters in $\begin{array}{llll}\text { finishing } \quad \text { pigs. } & \text { Livest }\end{array}$ https://doi.org/10.1016/j.livsci.2020.104185.

37. Ngapo TM, Martin JF, Dransfield E. International preferences for pork appearance: I. Consumer choices. Food Qual Prefer. 2007;18(1):26-36. https://doi.org/10.1016/j.foodqual.2005.07.001.

38. Suo C, Yin Y, Wang X, Lou X, Song D, Wang X, et al. Effects of lactobacillus plantarum ZJ316 on pig growth and pork quality. BMC Vet Res. 2012;8:89. https://doi.org/10.1186/1746-6148-8-89.

39. Zhou X, Wang Y, Gu Q, Li W. Effect of dietary probiotic, Bacillus coagulans, on growth performance, chemical composition, and meat quality of Guangxi Yellow chicken. Poult Sci. 2010;89(3):588-93. https://doi.org/10.3382/ps.2009-00319.

40. Fernandez X, Monin G, Talmant A, Mourot J, Lebret B. Influence of intramuscular fat content on the quality of pig meat - 1. Composition of the lipid fraction and sensory characteristics of m. longissimus lumborum. Meat Sci. 1999;53(1):59-65. https://doi.org/10.1016/s0309-1740(99)00037-6.

41. Madeira MS, Alfaia CM, Costa P, Lopes PA, Lemos JP, Bessa RJ, et al. The combination of arginine and leucine supplementation of reduced crude protein diets for boars increases eating quality of pork. J Anim Sci. 2014;92(5):2030-40. https://doi.org/10.2527/jas.2013-6876.

42. Fernandez X, Monin G, Talmant A, Mourot J, Lebret B. Influence of intramuscular fat content on the quality of pig meat -2 . Consumer acceptability of $\mathrm{m}$. longissimus lumborum. Meat Sci. 1999;53(1):67-72. https://doi.org/10.1016/s03091740(99)00038-8.

43. Karlsson A, Enfält AC, Essén-Gustavsson B, Lundström K, Rydhmer L, Stern S. Muscle histochemical and biochemical properties in relation to meat quality during selection for increased lean tissue growth rate in pigs. J Anim Sci. 1993;71(4):9308. https://doi.org/10.2527/1993.714930x.

44. Wood JD, Nute GR, Richardson RI, Whittington FM, Southwood O, Plastow G, et al. Effects of breed, diet and muscle on fat deposition and eating quality in pigs. Meat Sci. 2004;67(4):651-67. https://doi.org/10.1016/j.meatsci.2004.01.007.

45. Yu M, Li Z, Rong T, Wang G, Liu Z, Chen W, et al. Different dietary starch sources alter the carcass traits, meat quality, and the profile of muscle amino acid and fatty acid in finishing pigs. J Anim Sci Biotechnol. 2020;11:78. https://doi.org/10.1186/s40104-020-00484-9. 
46. Hu CJ, Jiang QY, Zhang T, Yin YL, Li FN, Deng JP, et al. Dietary supplementation with arginine and glutamic acid modifies growth performance, carcass traits, and meat quality in growing-finishing pigs. J Anim Sci. 2017;95(6):2680-9. https://doi.org/10.2527/jas.2017.1388.

47. Lorenzo JM, Franco D. Fat effect on physico-chemical, microbial and textural changes through the manufactured of dry-cured foal sausage Lipolysis, proteolysis and sensory properties. Meat Sci. 2012;92(4):704-14. https://doi.org/10.1016/j.meatsci.2012.06.026.

48. Liu YH, Li YY, Feng XC, Wang Z, Xia ZF. Dietary supplementation with Clostridium butyricum modulates serum lipid metabolism, meat quality, and the amino acid and fatty acid composition of Peking ducks. Poult Sci. 2018;97(9):321829. https://doi.org/10.3382/ps/pey162.

49. Ren M, Zhang SH, Zeng XF, Liu H, Qiao SY. Branched-chain amino acids are beneficial to maintain growth performance and intestinal immune-related function in weaned piglets fed protein restricted diet. Asian-Australas J Anim Sci. 2015;28(12):1742-50. https://doi.org/10.5713/ajas.14.0131.

50. Liao SF, Wang T, Regmi N. Lysine nutrition in swine and the related monogastric animals: muscle protein biosynthesis and beyond. Springerplus. 2015;4:147. https://doi.org/10.1186/s40064-015-0927-5.

51. Shikata N, Maki Y, Noguchi Y, Mori M, Hanai T, Takahashi M, et al. Multi-layered network structure of amino acid (AA) metabolism characterized by each essential AA-deficient condition. Amino Acids. 2007;33(1):113-21. https://doi.org/10.1007/s00726-006-0412-0.

52. Wang W, Wu Z, Dai Z, Yang Y, Wang J, Wu G. Glycine metabolism in animals and humans: implications for nutrition and health. Amino Acids. 2013;45(3):46377. https://doi.org/10.1007/s00726-013-1493-1.

53. Nie CX, He T, Zhang WJ, Zhang GL, Ma X. Branched chain amino acids: beyond nutrition metabolism. Int J Mol Sci. 2018;19(4):954. https://doi.org/10.3390/ijms19040954.

54. Huang LL, Ren PP, Ouyang ZC, Wei T, Kong XF, Li TJ, et al. Effect of fermented feed on growth performance, holistic metabolism and fecal microbiota in weanling piglets. Anim Feed Sci Technol. 2020;266:12. https://doi.org/10.1016/j.anifeedsci.2020.114505.

55. Liu Y, Kong X, Jiang G, Tan BE, Deng J, Yang X, et al. Effects of dietary protein/energy ratio on growth performance, carcass trait, meat quality, and plasma metabolites in pigs of different genotypes. J Anim Sci Biotechnol. 2015;6(4):43544. https://doi.org/10.1186/s40104-015-0036-x. 
56. Cui L, Wang H, Ding Y, Li J, Li J. Changes in the blood routine, biochemical indexes and the pro-inflammatory cytokine expressions of peripheral leukocytes in postpartum dairy cows with metritis. BMC Vet Res. 2019;15(1):157. https://doi.org/10.1186/s12917-019-1912-y.

57. Wood JD, Richardson RI, Nute GR, Fisher AV, Campo MM, Kasapidou E, et al. Effects of fatty acids on meat quality: a review. Meat Sci. 2004;66(1):21-32. https://doi.org/10.1016/S0309-1740(03)00022-6.

58. Aboagye G, Zappaterra M, Pasini F, Dall'Olio S, Davoli R, Costa LN. Fatty acid composition of the intramuscular fat in the longissimus thoracis muscle of ApuloCalabrese and crossbreed pigs. Livest Sci. 2020;232:103878. https://doi.org/10.1016/j.livsci.2019.103878.

59. Zhang YF, Zhang JJ, Gong HF, Cui LL, Zhang WC, Ma JW, et al. Genetic correlation of fatty acid composition with growth, carcass, fat deposition and meat quality traits based on GWAS data in six pig populations. Meat Sci. 2019;150:4755. https://doi.org/10.1016/j.meatsci.2018.12.008.

60. Ross GR, Van Nieuwenhove CP, González SN. Fatty acid profile of pig meat after probiotic administration. J Agric Food Chem. 2012;60(23):5974-8. https://doi.org/10.1021/jf205360h.

61. Li X, Cao ZH, Yang YT, Chen L, Liu JP, Lin QY, et al. Correlation between jejunal microbial diversity and muscle fatty acids deposition in broilers reared at different ambient temperatures. Sci Rep. 2019;9:11022. https://doi.org/10.1038/s41598-01947323-0.

62. Cheng CS, Liu ZH, Zhou YF, Wei HK, Zhang XM, Xia M, et al. Effect of oregano essential oil supplementation to a reduced-protein, amino acid-supplemented diet on meat quality, fatty acid composition, and oxidative stability of Longissimus thoracis muscle in growing-finishing pigs. Meat Sci. 2017;133:103-9. https://doi.org/10.1016/j.meatsci.2017.06.011.

63. Cameron ND, Enser M, Nute GR, Whittington FM, Penman JC, Fisken AC, et al. Genotype with nutrition interaction on fatty acid composition of intramuscular fat and the relationship with flavour of pig meat. Meat Sci. 2000;55(2):187-95. https://doi.org/10.1016/s0309-1740(99)00142-4.

64. Li XP, Luo T, Li J, Fan YW, Liu R, Hu JN, et al. Linolelaidic acid induces a stronger proliferative effect on human umbilical vein smooth muscle cells compared to elaidic acid. Lipids. 2013;48(4):395-403. https://doi.org/10.1007/s11745-0123754-2.

65. Lefaucheur L, Ecolan P, Plantard L, Gueguen N. New insights into muscle fiber types in the pig. J Histochem Cytochem. 2002;50(5):719-30. https://doi.org/10.1177/002215540205000513. 
66. Fazarinc G, Vrecl M, Poklukar K, Škrlep M, Batorek-Lukač N, Brankovič J, et al. Expression of myosin heavy chain and some energy metabolism-related genes in the longissimus dorsi muscle of krškopolje pigs: effect of the production system. Front Vet Sci. 2020;7:533936. https://doi.org/10.3389/fvets.2020.533936.

67. Luo P, Luo L, Zhao W, Wang L, Sun L, Wu H, et al. Dietary thymol supplementation promotes skeletal muscle fibre type switch in longissimus dorsi of finishing pigs. J Anim Physiol Anim Nutr. 2020;104(2):570-8. https://doi.org/10.1111/jpn.13269.

68. Chargé SBP, Rudnicki MA. Cellular and molecular regulation of muscle regeneration. Physiol Rev. 2004;84(1):209-38. https://doi.org/10.1152/physrev.00019.2003.

69. Langley B, Thomas M, Bishop A, Sharma M, Gilmour S, Kambadur R. Myostatin inhibits myoblast differentiation by down-regulating MyoD expression. J Biol Chem. 2002;277(51):49831-40. https://doi.org/10.1074/jbc.M204291200.

70. Willoughby DS, Nelson MJ. Myosin heavy-chain mRNA expression after a single session of heavy-resistance exercise. Med Sci Sports Exerc. 2002;34(8):1262-9. https://doi.org/10.1097/00005768-200208000-00006.

71. Ying F, Zhang L, Bu G, Xiong Y, Zuo B. Muscle fiber-type conversion in the transgenic pigs with overexpression of $\mathrm{PGC} 1 \alpha$ gene in muscle. Biochem Biophys Res Commun. 2016;480(4):669-74. https://doi.org/10.1016/j.bbrc.2016.10.113.

72. Kucharski M, Kaczor U. Desaturaza stearylo-CoA - regulator metabolizmu lipidów Stearoyl-CoA desaturase - the lipid metabolism regulator. Adv Hyg Exp Med. 2014;68:334-42. https://doi.org/10.5604/17322693.1095856.

73. Jeong J, Kwon EG, Im SK, Seo KS, Baik M. Expression of fat deposition and fat removal genes is associated with intramuscular fat content in longissimus dorsi muscle of Korean cattle steers. J Anim Sci. 2012;90(6):2044-53. https://doi.org/10.2527/jas.2011-4753.

74. Zappaterra M, Deserti M, Mazza R, Braglia S, Zambonelli P, Davoli R. A gene and protein expression study on four porcine genes related to intramuscular fat deposition. $\quad$ Meat Sci. 2016;121:27-32. https://doi.org/10.1016/j.meatsci.2016.05.007. 
A

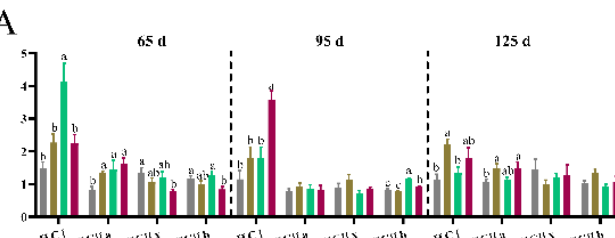

c

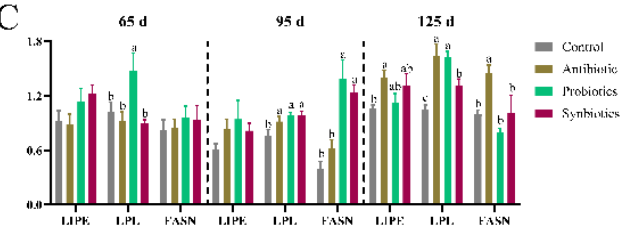

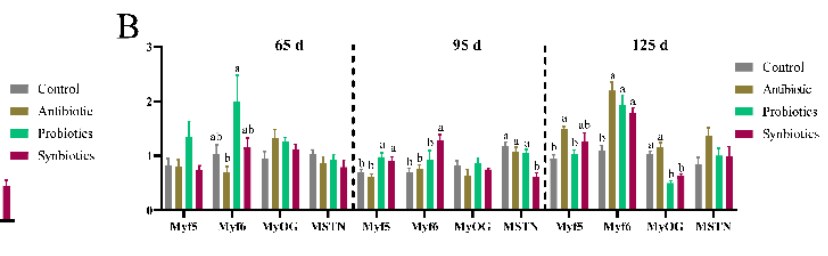

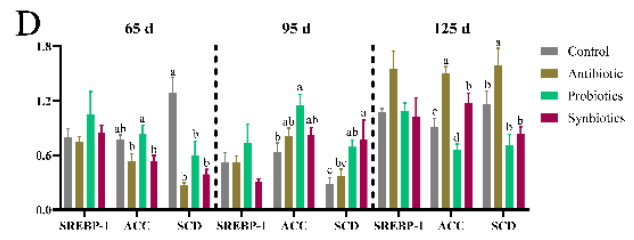

961 Fig. 1 Effects of probiotics or synbiotics addition in sows' diets on mRNA expression 962 of myosin heavy chain (MyHC) isoforms (A), myogenic regulatory factors (MRFs)(B), 963 and lipid metabolism related genes (C and D) in the longissimus thoracis muscle of 964 offspring pigs at 65-, 95-, and 125-day-old. 65 d, 65-day-old; 95 d, 95-day-old; 125-d, 965 125-day-old. ACC, acetyl-CoA carboxylase; FASN, fatty acid synthase; LIPE, 966 hormone-sensitive triglyceride lipase; $L P L$, lipoprotein lipase; $M y f 5$, myogenic factor 967 5; Myf6, myogenic factor 6; MyOG, myogenin; $M S T N$, myostatin; $S C D$, stearoyl-CoA 968 desaturase; SREBP-1, sterol-regulatory element-binding protein-1. 


\section{Table 1}

970 Effects of probiotics or synbiotics addition in sows' diets on growth performance of

971 offspring pigs.

\begin{tabular}{lcccccc}
\hline Items & $\begin{array}{c}\text { Control } \\
\text { group }\end{array}$ & $\begin{array}{c}\text { Antibiotic } \\
\text { group }\end{array}$ & $\begin{array}{c}\text { Probiotics } \\
\text { group }\end{array}$ & $\begin{array}{c}\text { Synbiotics } \\
\text { group }\end{array}$ & SEM & \multirow{2}{*}{$P$ values } \\
\hline
\end{tabular}

Body weight $(\mathrm{kg})$

$\begin{array}{lcccccc}\text { 35-day-old } & 4.97 & 4.90 & 4.80 & 4.66 & 0.172 & 0.609 \\ \text { 65-day-old } & 9.37 & 8.99 & 9.54 & 9.26 & 0.190 & 0.243 \\ \text { 95-day-old } & 14.05^{\mathrm{ab}} & 12.37^{\mathrm{b}} & 14.61^{\mathrm{a}} & 13.32^{\mathrm{ab}} & 0.528 & 0.032 \\ \text { 125-day-old } & 22.67 & 26.19 & 25.36 & 27.19 & 1.289 & 0.097\end{array}$

Average daily gain $(\mathrm{kg} / \mathrm{d})$

$\begin{array}{lllllll}\text { 35-65 day-old } & 0.15 & 0.14 & 0.15 & 0.16 & 0.005 & 0.079 \\ \text { 66-95 day-old } & 0.18 & 0.15 & 0.18 & 0.16 & 0.012 & 0.284 \\ \text { 96-125 day-old } & 0.27 & 0.27 & 0.25 & 0.26 & 0.027 & 0.902\end{array}$

Average daily feed intake $(\mathrm{kg} / \mathrm{d})$

$\begin{array}{lllllll}35-65 \text { day-old } & 0.41 & 0.41 & 0.44 & 0.41 & 0.012 & 0.330 \\ 66-95 \text { day-old } & 0.64^{\mathrm{b}} & 0.55^{\mathrm{c}} & 0.75^{\mathrm{a}} & 0.70^{\mathrm{ab}} & 0.024 & <.0001 \\ 96-125 \text { day-old } & 0.92^{\mathrm{b}} & 1.32^{\mathrm{a}} & 0.91^{\mathrm{b}} & 1.10^{\mathrm{b}} & 0.065 & <.0001\end{array}$

Feed/Gain ratio

\begin{tabular}{lcccccc} 
35-65 day-old & 3.02 & 2.86 & 2.68 & 2.78 & 0.102 & 0.136 \\
66-95 day-old & 3.56 & 3.82 & 3.75 & 4.25 & 0.220 & 0.173 \\
$96-125$ day-old & $3.32^{\mathrm{b}}$ & $4.17^{\mathrm{a}}$ & $4.00^{\mathrm{ab}}$ & $3.90^{\mathrm{ab}}$ & 0.211 & 0.040 \\
\hline
\end{tabular}

972 Data are presented as means with pooled SEM. Values in the same row with different 973 superscript letters were significantly different $(P<0.05)$. The replicates per group 974 during 35-65 and 66-95 day-old were 8; during 96-125 day-old, the replicates of the 975 control group, antibiotic group, probiotics group, and synbiotics group were 8, 6, 8, and 976 6, respectively. 
978 Effects of probiotics or synbiotics addition in sows' diets on carcass traits of offspring 979 pigs.

\begin{tabular}{lcccccc}
\hline Items & $\begin{array}{c}\text { Control } \\
\text { group }\end{array}$ & $\begin{array}{c}\text { Antibiotic } \\
\text { group }\end{array}$ & $\begin{array}{c}\text { Probiotics } \\
\text { group }\end{array}$ & $\begin{array}{c}\text { Synbiotics } \\
\text { group }\end{array}$ & SEM & $P$ values \\
\hline
\end{tabular}

Carcass weight $(\mathrm{kg})$

\begin{tabular}{lcccccc} 
65-day-old & $5.00^{\mathrm{ab}}$ & $4.71^{\mathrm{b}}$ & $5.27^{\mathrm{a}}$ & $4.82^{\mathrm{b}}$ & 0.108 & 0.006 \\
95-day-old & $8.25^{\mathrm{a}}$ & $6.36^{\mathrm{b}}$ & $7.73^{\mathrm{ab}}$ & $7.32^{\mathrm{ab}}$ & 0.445 & 0.037 \\
125-day-old & 13.83 & 16.40 & 14.60 & 16.25 & 0.817 & 0.091 \\
\multicolumn{2}{l}{ Muscle percentage $(\%)$} & & & & & \\
65-day-old & 21.56 & 21.09 & 22.49 & 21.17 & 0.491 & 0.191 \\
95-day-old & 21.23 & 20.67 & 22.00 & 21.51 & 0.389 & 0.130 \\
125-day-old & $23.87^{\mathrm{a}}$ & $23.11^{\mathrm{ab}}$ & $23.53^{\mathrm{a}}$ & $22.44^{\mathrm{b}}$ & 0.236 & 0.002
\end{tabular}

Fat percentage $(\%)$

$\begin{array}{lcccccc}\text { 65-day-old } & 12.14 & 12.10 & 13.31 & 11.78 & 0.396 & 0.052 \\ \text { 95-day-old } & 15.24^{\mathrm{a}} & 12.47^{\mathrm{b}} & 15.29^{\mathrm{a}} & 15.01^{\mathrm{a}} & 0.662 & 0.011 \\ \text { 125-day-old } & 17.73^{\mathrm{b}} & 21.49^{\mathrm{a}} & 22.28^{\mathrm{a}} & 20.89^{\mathrm{a}} & 0.548 & <.0001\end{array}$

Bone percentage $(\%)$

$\begin{array}{lcccccc}\text { 65-day-old } & 11.80 & 11.89 & 11.95 & 11.98 & 0.190 & 0.915 \\ \text { 95-day-old } & 10.13 & 10.44 & 10.57 & 9.99 & 0.273 & 0.424 \\ \text { 125-day-old } & 9.15 & 8.55 & 9.60 & 9.25 & 0.261 & 0.069\end{array}$

Leaf fat ratio $(\mathrm{g} / \mathrm{kg})$

$\begin{array}{lcccccc}\text { 65-day-old } & 6.93 & 6.04 & 7.05 & 6.75 & 0.376 & 0.248 \\ \text { 95-day-old } & 11.41^{\mathrm{a}} & 8.09^{\mathrm{b}} & 7.77^{\mathrm{b}} & 11.17^{\mathrm{a}} & 0.587 & <.0001 \\ \text { 125-day-old } & 16.77^{\mathrm{b}} & 17.88^{\mathrm{b}} & 21.54^{\mathrm{a}} & 19.33^{\mathrm{ab}} & 0.925 & 0.005\end{array}$

Backfat thickness (mm)

$\begin{array}{lcccccc}\text { 65-day-old } & 13.27^{\mathrm{b}} & 12.78^{\mathrm{b}} & 14.65^{\mathrm{a}} & 13.90^{\mathrm{ab}} & 0.396 & 0.014 \\ \text { 95-day-old } & 18.79 & 16.78 & 18.46 & 16.98 & 0.611 & 0.060 \\ \text { 125-day-old } & 24.75^{\mathrm{b}} & 28.81^{\mathrm{a}} & 27.53^{\mathrm{a}} & 28.15^{\mathrm{a}} & 0.832 & 0.009\end{array}$

Loin-eye muscle area $\left(\mathrm{cm}^{2}\right)$

\begin{tabular}{lcccccc} 
65-day-old & 4.21 & 4.29 & 4.45 & 4.19 & 0.200 & 0.788 \\
95-day-old & $4.33^{\mathrm{ab}}$ & $4.22^{\mathrm{b}}$ & $4.39^{\mathrm{ab}}$ & $5.01^{\mathrm{a}}$ & 0.200 & 0.038 \\
125-day-old & $7.20^{\mathrm{a}}$ & $7.36^{\mathrm{a}}$ & $7.67^{\mathrm{a}}$ & $5.57^{\mathrm{b}}$ & 0.282 & $<.0001$ \\
\hline
\end{tabular}

980 Data are presented as means with pooled SEM. Values in the same row with different 981 superscript letters were significantly different $(P<0.05)$. The replicates per group at 982 65- and 95-day-old were 8. At 125-day-old, the replicates of the control group, 983 antibiotic group, probiotics group, and synbiotics group are 8, 6, 8, and 6, respectively. 
985 Effects of probiotics or synbiotics addition in sows' diets on meat quality of offspring 986 pigs.

\begin{tabular}{|c|c|c|c|c|c|c|}
\hline Items & $\begin{array}{l}\text { Control } \\
\text { group }\end{array}$ & $\begin{array}{c}\text { Antibiotic } \\
\text { group }\end{array}$ & $\begin{array}{c}\text { Probiotics } \\
\text { group }\end{array}$ & $\begin{array}{c}\text { Synbiotics } \\
\text { group }\end{array}$ & SEM & $P$ values \\
\hline \multicolumn{7}{|c|}{ Marbling score } \\
\hline 65-day-old & 1.75 & 1.63 & 1.38 & 1.50 & 0.180 & 0.502 \\
\hline 95-day-old & $1.88^{\mathrm{a}}$ & $1.38^{\mathrm{ab}}$ & $1.25^{\mathrm{ab}}$ & $1.38^{\mathrm{ab}}$ & 0.190 & 0.120 \\
\hline 125-day-old & 1.50 & 1.67 & 1.25 & 1.67 & 0.193 & 0.376 \\
\hline \multicolumn{7}{|c|}{ Meat color score } \\
\hline 65-day-old & 3.13 & 2.88 & 2.75 & 2.50 & 0.336 & 0.620 \\
\hline 95-day-old & 2.50 & 2.38 & 2.38 & 2.63 & 0.184 & 0.740 \\
\hline 125-day-old & 2.75 & 3.17 & 2.50 & 2.83 & 0.208 & 0.188 \\
\hline \multicolumn{7}{|l|}{$\mathrm{L}^{*}$ value } \\
\hline 65-day-old & $51.01^{\mathrm{a}}$ & $50.66^{\mathrm{a}}$ & $48.11^{\mathrm{b}}$ & $50.75^{\mathrm{a}}$ & 0.623 & 0.008 \\
\hline 95-day-old & $50.16^{\mathrm{ab}}$ & $49.67^{\mathrm{ab}}$ & $51.78^{\mathrm{a}}$ & $48.50^{\mathrm{b}}$ & 0.766 & 0.041 \\
\hline 125-day-old & $50.94^{\mathrm{a}}$ & $49.49^{\mathrm{ab}}$ & $52.35^{\mathrm{a}}$ & $47.33^{\mathrm{b}}$ & 0.993 & 0.011 \\
\hline \multicolumn{7}{|l|}{$a^{*}$ value } \\
\hline 65-day-old & 19.58 & 19.11 & 19.47 & 18.50 & 0.617 & 0.605 \\
\hline 95-day-old & $18.44^{\mathrm{b}}$ & $18.01^{\mathrm{b}}$ & $17.12^{\mathrm{c}}$ & $19.86^{\mathrm{a}}$ & 0.226 & $<.0001$ \\
\hline $\begin{array}{l}125 \text {-day-old } \\
b^{*} \text { value }\end{array}$ & 18.14 & 17.89 & 17.17 & 17.16 & 0.499 & 0.377 \\
\hline 65-day-old & 6.87 & 6.82 & 7.50 & 7.05 & 0.192 & 0.071 \\
\hline 95-day-old & 6.72 & 6.59 & 6.06 & 6.47 & 0.213 & 0.171 \\
\hline $\begin{array}{l}\text { 125-day-old } \\
\mathrm{pH}_{45 \min }\end{array}$ & $7.07^{\mathrm{ab}}$ & $6.50^{\mathrm{b}}$ & $7.30^{\mathrm{a}}$ & $6.48^{\mathrm{b}}$ & 0.187 & 0.008 \\
\hline 65-day-old & 6.55 & 6.55 & 6.50 & 6.52 & 0.035 & 0.744 \\
\hline 95-day-old & $6.54^{\mathrm{b}}$ & $6.67^{\mathrm{ab}}$ & $6.74^{\mathrm{a}}$ & $6.55^{\mathrm{b}}$ & 0.037 & 0.002 \\
\hline $\begin{array}{l}\text { 125-day-old } \\
\mathrm{pH}_{24 \mathrm{~h}}\end{array}$ & \multicolumn{5}{|c|}{$\mathrm{pH}_{24 \mathrm{~h}}$} & 0.069 \\
\hline 65-day-old & 5.46 & 5.49 & 5.61 & 5.45 & 0.053 & 0.134 \\
\hline 95-day-old & 5.46 & 5.44 & 5.46 & 5.49 & 0.013 & 0.088 \\
\hline 125-day-old & 5.46 & 5.53 & 5.50 & 5.50 & 0.025 & 0.245 \\
\hline \multicolumn{7}{|l|}{ Drip loss $(\%)$} \\
\hline 65-day-old & $6.32^{\mathrm{a}}$ & $5.64^{\mathrm{a}}$ & $4.41^{\mathrm{b}}$ & $2.96^{\mathrm{c}}$ & 0.340 & $<.0001$ \\
\hline 95-day-old & 3.42 & 3.35 & 2.98 & 2.78 & 0.313 & 0.437 \\
\hline 125-day-old & 4.82 & 3.31 & 3.82 & 3.94 & 0.485 & 0.182 \\
\hline \multicolumn{7}{|c|}{ Cooking yield (\%) } \\
\hline 65-day-old & $63.01^{\mathrm{bc}}$ & $60.94^{c}$ & $67.02^{\mathrm{a}}$ & $65.22^{\mathrm{ab}}$ & 1.087 & 0.003 \\
\hline 95-day-old & 70.92 & 69.26 & 70.99 & 68.53 & 0.806 & 0.098 \\
\hline
\end{tabular}




\begin{tabular}{lcccccc} 
125-day-old & $68.57^{\mathrm{b}}$ & $78.41^{\mathrm{a}}$ & $68.50^{\mathrm{b}}$ & $66.94^{\mathrm{b}}$ & 2.331 & 0.012 \\
Shear force (N) & & & & & \\
65-day-old & $61.50^{\mathrm{b}}$ & $62.96^{\mathrm{b}}$ & $58.73^{\mathrm{b}}$ & $75.28^{\mathrm{a}}$ & 2.311 & $<.0001$ \\
95-day-old & 73.25 & 64.61 & 65.74 & 70.82 & 2.936 & 0.143 \\
125-day-old & $91.94^{\mathrm{b}}$ & $101.74^{\mathrm{a}}$ & $77.14^{\mathrm{c}}$ & $84.41^{\mathrm{c}}$ & 2.516 & $<.0001$ \\
\hline
\end{tabular}

987 Data are presented as means with pooled SEM. Values in the same row with different 988 superscript letters were significantly different $(P<0.05)$. The replicates per group at 989 65- and 95-day-old were 8. At 125-day-old, the replicates of the control group, 990 antibiotic group, probiotics group, and synbiotics group are 8,6,8, and 6, respectively. 991 L*, lightness; $a^{*}$, redness; $b^{*}$, yellowness. 
993 Effects of probiotics or synbiotics addition in sows' diets on amino acids content in the 994 longissimus thoracis muscle of offspring pigs (g/100 g fresh muscle).

\begin{tabular}{|c|c|c|c|c|c|c|}
\hline Item & $\begin{array}{l}\text { Control } \\
\text { group }\end{array}$ & $\begin{array}{c}\text { Antibiotic } \\
\text { group }\end{array}$ & $\begin{array}{l}\text { Probiotics } \\
\text { group }\end{array}$ & $\begin{array}{c}\text { Synbiotics } \\
\text { group }\end{array}$ & SEM & $P$ values \\
\hline \multicolumn{7}{|l|}{$\mathrm{CP}$} \\
\hline 65-day-old & $23.39^{\mathrm{ab}}$ & $23.80^{\mathrm{ab}}$ & $24.50^{\mathrm{a}}$ & $23.17^{\mathrm{b}}$ & 0.318 & 0.032 \\
\hline 95-day-old & 22.12 & 22.65 & 22.83 & 22.26 & 0.316 & 0.365 \\
\hline 125-day-old & $22.21^{\mathrm{ab}}$ & $22.79^{\mathrm{a}}$ & $22.06^{\mathrm{ab}}$ & $21.44^{\mathrm{b}}$ & 0.252 & 0.016 \\
\hline \multicolumn{7}{|l|}{ Ala } \\
\hline 65-day-old & 1.20 & 1.20 & 1.18 & 1.20 & 0.031 & 0.975 \\
\hline 95-day-old & 1.06 & 1.14 & 1.12 & 1.07 & 0.031 & 0.237 \\
\hline 125-day-old & 1.17 & 1.23 & 1.27 & 1.21 & 0.029 & 0.126 \\
\hline \multicolumn{7}{|l|}{ Asp } \\
\hline 65-day-old & $1.80^{\mathrm{a}}$ & $1.80^{\mathrm{a}}$ & $1.63^{b}$ & $1.70^{\mathrm{ab}}$ & 0.038 & 0.009 \\
\hline 95-day-old & $1.51^{\mathrm{b}}$ & $1.55^{\mathrm{ab}}$ & $1.68^{\mathrm{a}}$ & $1.69^{\mathrm{a}}$ & 0.044 & 0.014 \\
\hline 125-day-old & $1.76^{\mathrm{b}}$ & $1.91^{\mathrm{a}}$ & $1.94^{\mathrm{a}}$ & $1.77^{\mathrm{b}}$ & 0.041 & 0.004 \\
\hline \multicolumn{7}{|l|}{ Glu } \\
\hline 65-day-old & 2.63 & 2.63 & 2.53 & 2.54 & 0.070 & 0.632 \\
\hline 95-day-old & 2.63 & 2.68 & 2.82 & 2.81 & 0.066 & 0.144 \\
\hline 125-day-old & 2.84 & 2.96 & 3.03 & 3.00 & 0.070 & 0.215 \\
\hline \multicolumn{7}{|l|}{ Gly } \\
\hline 65-day-old & $1.09^{\mathrm{a}}$ & $1.08^{\mathrm{a}}$ & $0.96^{\mathrm{b}}$ & $1.01^{\mathrm{ab}}$ & 0.034 & 0.047 \\
\hline 95-day-old & 0.95 & 1.01 & 1.05 & 1.06 & 0.035 & 0.118 \\
\hline 125-day-old & 0.98 & 0.96 & 1.01 & 0.96 & 0.040 & 0.817 \\
\hline \multicolumn{7}{|l|}{ Pro } \\
\hline 65-day-old & 0.94 & 0.96 & 1.07 & 0.96 & 0.039 & 0.094 \\
\hline 95-day-old & $1.17^{\mathrm{ab}}$ & $1.33^{\mathrm{a}}$ & $1.14^{\mathrm{ab}}$ & $0.98^{\mathrm{b}}$ & 0.061 & 0.006 \\
\hline 125-day-old & 1.04 & 0.90 & 0.97 & 1.07 & 0.050 & 0.136 \\
\hline \multicolumn{7}{|l|}{ Ser } \\
\hline 65-day-old & 0.69 & 0.71 & 0.67 & 0.68 & 0.020 & 0.518 \\
\hline 95-day-old & 0.71 & 0.74 & 0.76 & 0.75 & 0.017 & 0.172 \\
\hline 125-day-old & $0.75^{\mathrm{b}}$ & $0.75^{\mathrm{b}}$ & $0.78^{\mathrm{b}}$ & $0.84^{\mathrm{a}}$ & 0.019 & 0.012 \\
\hline \multicolumn{7}{|l|}{ Tyr } \\
\hline 65-day-old & 0.71 & 0.67 & 0.70 & 0.70 & 0.016 & 0.341 \\
\hline 95-day-old & 0.63 & 0.70 & 0.71 & 0.70 & 0.038 & 0.428 \\
\hline 125-day-old & 0.75 & 0.70 & 0.75 & 0.80 & 0.026 & 0.176 \\
\hline \multicolumn{7}{|l|}{ Arg } \\
\hline 65-day-old & 1.34 & 1.31 & 1.27 & 1.31 & 0.026 & 0.378 \\
\hline 95-day-old & $1.21^{\mathrm{b}}$ & $1.30^{\mathrm{a}}$ & $1.35^{\mathrm{a}}$ & $1.34^{\mathrm{a}}$ & 0.032 & 0.017 \\
\hline
\end{tabular}


125-day-old

$1.34 \quad 1.37$

1.43

1.38

$0.031 \quad 0.256$

His

\begin{tabular}{|c|c|c|c|c|c|c|}
\hline 65-day-old & $0.80^{\mathrm{b}}$ & $0.75^{\mathrm{b}}$ & $0.91^{\mathrm{a}}$ & $0.79^{\mathrm{a}}$ & 0.021 & $<.0001$ \\
\hline 95-day-old & $0.94^{\mathrm{a}}$ & $0.90^{\mathrm{ab}}$ & $0.82^{\mathrm{b}}$ & $0.85^{\mathrm{ab}}$ & 0.027 & 0.022 \\
\hline 125-day-old & $0.89^{\mathrm{b}}$ & $0.95^{\mathrm{b}}$ & $0.94^{\mathrm{b}}$ & $1.08^{\mathrm{a}}$ & 0.027 & $<.0001$ \\
\hline \multicolumn{7}{|l|}{ Ile } \\
\hline 65-day-old & 0.90 & 0.90 & 0.83 & 0.87 & 0.021 & 0.056 \\
\hline 95-day-old & $0.82^{\mathrm{b}}$ & $0.83^{b}$ & $0.91^{\mathrm{a}}$ & $0.91^{\mathrm{a}}$ & 0.021 & 0.002 \\
\hline 125-day-old & 0.99 & 1.04 & 1.06 & 0.98 & 0.024 & 0.075 \\
\hline \multicolumn{7}{|l|}{ Leu } \\
\hline 65-day-old & 1.74 & 1.71 & 1.61 & 1.68 & 0.034 & 0.079 \\
\hline 95-day-old & 1.43 & 1.42 & 1.50 & 1.51 & 0.037 & 0.252 \\
\hline 125-day-old & $1.67^{\mathrm{b}}$ & $1.80^{\mathrm{a}}$ & $1.82^{\mathrm{a}}$ & $1.71^{\mathrm{ab}}$ & 0.040 & 0.033 \\
\hline \multicolumn{7}{|l|}{ Lys } \\
\hline 65-day-old & 1.77 & 1.77 & 1.64 & 1.73 & 0.040 & 0.105 \\
\hline 95-day-old & $1.59^{\mathrm{b}}$ & $1.58^{\mathrm{b}}$ & $1.72^{\mathrm{ab}}$ & $1.78^{\mathrm{a}}$ & 0.047 & 0.014 \\
\hline 125-day-old & 1.89 & 1.96 & 2.02 & 1.91 & 0.045 & 0.194 \\
\hline \multicolumn{7}{|l|}{ Met } \\
\hline 65-day-old & 0.53 & 0.54 & 0.50 & 0.49 & 0.016 & 0.278 \\
\hline 95-day-old & 0.54 & 0.52 & 0.54 & 0.53 & 0.013 & 0.612 \\
\hline 125-day-old & 0.62 & 0.65 & 0.66 & 0.66 & 0.019 & 0.362 \\
\hline \multicolumn{7}{|l|}{ Phe } \\
\hline 65-day-old & 0.87 & 0.84 & 0.86 & 0.87 & 0.021 & 0.789 \\
\hline 95-day-old & 0.86 & 0.81 & 0.84 & 0.87 & 0.020 & 0.193 \\
\hline 125-day-old & $0.90^{\mathrm{b}}$ & $0.91^{\mathrm{ab}}$ & $0.96^{\mathrm{ab}}$ & $1.00^{\mathrm{a}}$ & 0.025 & 0.039 \\
\hline \multicolumn{7}{|l|}{ Thr } \\
\hline 65-day-old & 0.93 & 0.93 & 0.87 & 0.90 & 0.018 & 0.051 \\
\hline 95-day-old & 0.84 & 0.88 & 0.92 & 0.89 & 0.024 & 0.120 \\
\hline 125-day-old & 0.96 & 0.97 & 1.00 & 0.99 & 0.024 & 0.493 \\
\hline \multicolumn{7}{|l|}{ Val } \\
\hline 65-day-old & 0.97 & 0.97 & 0.90 & 0.95 & 0.023 & 0.107 \\
\hline 95-day-old & 0.96 & 0.93 & 0.98 & 1.00 & 0.023 & 0.130 \\
\hline 125-day-old & 1.08 & 1.11 & 1.14 & 1.12 & 0.027 & 0.447 \\
\hline \multicolumn{7}{|l|}{ EAA } \\
\hline 65-day-old & 9.83 & 9.72 & 9.49 & 9.59 & 0.195 & 0.637 \\
\hline 95-day-old & 9.17 & 9.18 & 9.58 & 9.68 & 0.216 & 0.233 \\
\hline 125-day-old & 10.35 & 10.76 & 11.03 & 10.84 & 0.234 & 0.190 \\
\hline \multicolumn{7}{|l|}{ NEAA } \\
\hline 65-day-old & 9.08 & 9.06 & 8.76 & 8.80 & 0.214 & 0.610 \\
\hline 95-day-old & 8.56 & 9.14 & 9.28 & 9.06 & 0.229 & 0.159 \\
\hline
\end{tabular}


$\begin{array}{lllllll}\text { 125-day-old } & 9.29 & 9.42 & 9.73 & 9.64 & 0.226 & 0.469\end{array}$

FAA

$\begin{array}{lllllll}\text { 65-day-old } & 8.06 & 8.03 & 7.57 & 7.76 & 0.181 & 0.211 \\ \text { 95-day-old } & 7.39 & 7.68 & 8.01 & 7.97 & 0.180 & 0.075 \\ \text { 125-day-old } & 8.09 & 8.43 & 8.66 & 8.31 & 0.188 & 0.176\end{array}$

TAA

$\begin{array}{lllllll}\text { 65-day-old } & 18.90 & 18.78 & 18.27 & 18.39 & 0.402 & 0.643\end{array}$

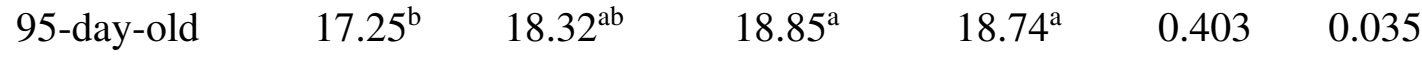

$\begin{array}{lllllll}\text { 125-day-old } & 19.64 & 20.18 & 20.76 & 20.4 & 0.451 & 0.303\end{array}$

995 Data are presented as means with pooled SEM. Values in the same row with different

996 superscript letters were significantly different $(P<0.05)$ The replicates per group at 65-

997 and 95-day-old were 8. At 125-day-old, the replicates of the control group, antibiotic

998 group, probiotics group, and synbiotics group are 8, 6, 8, and 6, respectively.

999 CP, crude protein; EAA, essential amino acids; NEAA, non-essential amino acids; FAA,

1000 flavor amino acids; TAA, total amino acids. The EAA included Arg, arginine; His,

1001 histidine; Ile, isoleucine; Leu, leucine; Lys, lysine; Met, methionine; Phe,

1002 phenylalanine; Thr, threonine; and Val, valine. The NEAA included Ala, alanine; Asp,

1003 aspartate; Glu, glutamate; Gly, glycine; Pro, proline; Ser, serine; and Tyr, tyrosine; The

1004 FAA, included Asp, Glu, Gly, Ala, and Arg. 
1006 Effects of probiotics or synbiotics addition in sows' diets on medium- and long-chain

1007 fatty acids content in longissimus thoracis muscle of offspring pigs (\%).

\begin{tabular}{|c|c|c|c|c|c|c|}
\hline Item & $\begin{array}{l}\text { Control } \\
\text { group }\end{array}$ & $\begin{array}{c}\text { Antibiotic } \\
\text { group }\end{array}$ & $\begin{array}{l}\text { Probiotics } \\
\text { group }\end{array}$ & $\begin{array}{c}\text { Synbiotics } \\
\text { group }\end{array}$ & SEM & $P$ values \\
\hline \multicolumn{7}{|c|}{ Intramuscular fat } \\
\hline 65-day-old & $2.72^{\mathrm{ab}}$ & $3.13^{\mathrm{a}}$ & $2.32^{b}$ & $3.24^{\mathrm{a}}$ & 0.231 & 0.035 \\
\hline 95-day-old & $2.62^{\mathrm{ab}}$ & $2.44^{\mathrm{ab}}$ & $3.21^{\mathrm{a}}$ & $1.52^{b}$ & 0.325 & 0.009 \\
\hline $\begin{array}{l}\text { 125-day-old } \\
\text { C10:0 }\end{array}$ & $2.15^{\mathrm{b}}$ & $2.07^{\mathrm{b}}$ & $1.79^{\mathrm{b}}$ & $2.80^{\mathrm{a}}$ & 0.197 & 0.012 \\
\hline 65-day-old & $0.024^{\mathrm{b}}$ & $0.023^{\mathrm{b}}$ & $0.021^{\mathrm{b}}$ & $0.028^{\mathrm{a}}$ & 0.001 & 0.004 \\
\hline 95-day-old & $0.022^{\mathrm{b}}$ & $0.024^{\mathrm{ab}}$ & $0.027^{\mathrm{a}}$ & $0.026^{\mathrm{a}}$ & 0.001 & 0.028 \\
\hline $\begin{array}{l}\text { 125-day-old } \\
\text { C12:0 }\end{array}$ & 0.024 & 0.023 & 0.026 & 0.029 & 0.002 & 0.145 \\
\hline 65-day-old & $0.036^{\mathrm{b}}$ & $0.039^{\mathrm{ab}}$ & $0.038^{\mathrm{ab}}$ & $0.042^{\mathrm{a}}$ & 0.001 & 0.039 \\
\hline 95-day-old & $0.041^{\mathrm{a}}$ & $0.030^{\mathrm{b}}$ & $0.035^{\mathrm{b}}$ & $0.031^{\mathrm{b}}$ & 0.002 & $<.0001$ \\
\hline $\begin{array}{l}\text { 125-day-old } \\
\text { C14:0 }\end{array}$ & $0.028^{\mathrm{a}}$ & $0.023^{\mathrm{b}}$ & $0.028^{\mathrm{a}}$ & $0.029^{\mathrm{a}}$ & 0.001 & 0.024 \\
\hline 65-day-old & $0.447^{b c}$ & $0.486^{\mathrm{ab}}$ & $0.423^{c}$ & $0.524^{\mathrm{a}}$ & 0.014 & $<.0001$ \\
\hline 95-day-old & $0.487^{\mathrm{b}}$ & $0.514^{\mathrm{ab}}$ & $0.559^{\mathrm{a}}$ & $0.536^{\mathrm{ab}}$ & 0.017 & 0.040 \\
\hline $\begin{array}{l}\text { 125-day-old } \\
\text { C15:0 }\end{array}$ & 0.497 & 0.505 & 0.474 & 0.509 & 0.027 & 0.772 \\
\hline 65-day-old & 0.024 & 0.029 & 0.026 & 0.027 & 0.001 & 0.152 \\
\hline 95-day-old & 0.022 & 0.024 & 0.023 & 0.026 & 0.001 & 0.156 \\
\hline $\begin{array}{l}\text { 125-day-old } \\
\text { C16:0 }\end{array}$ & $0.022^{\mathrm{a}}$ & $0.019^{\mathrm{ab}}$ & $0.017^{\mathrm{b}}$ & $0.016^{\mathrm{b}}$ & 0.001 & 0.001 \\
\hline 65-day-old & $8.137^{\mathrm{a}}$ & $8.176^{\mathrm{ab}}$ & $7.604^{b}$ & $8.355^{\mathrm{a}}$ & 0.162 & 0.017 \\
\hline 95-day-old & 8.334 & 8.209 & 8.643 & 8.301 & 0.141 & 0.172 \\
\hline $\begin{array}{l}\text { 125-day-old } \\
\text { C16:1 }\end{array}$ & 8.231 & 8.290 & 7.796 & 8.089 & 0.216 & 0.356 \\
\hline 65-day-old & 1.177 & 1.169 & 1.091 & 1.254 & 0.055 & 0.253 \\
\hline 95-day-old & $0.728^{c}$ & $0.906^{\mathrm{ab}}$ & $0.976^{\mathrm{a}}$ & $0.884^{\mathrm{b}}$ & 0.025 & $<.0001$ \\
\hline $\begin{array}{l}\text { 125-day-old } \\
\text { C17:0 }\end{array}$ & $0.785^{b}$ & $0.755^{\mathrm{b}}$ & $0.868^{\mathrm{a}}$ & $0.757^{\mathrm{b}}$ & 0.026 & 0.013 \\
\hline 65-day-old & 0.103 & 0.116 & 0.100 & 0.110 & 0.005 & 0.183 \\
\hline 95-day-old & 0.091 & 0.094 & 0.094 & 0.100 & 0.004 & 0.514 \\
\hline $\begin{array}{l}\text { 125-day-old } \\
\text { C18:0 }\end{array}$ & $0.082^{\mathrm{a}}$ & $0.078^{\mathrm{ab}}$ & $0.061^{\mathrm{b}}$ & $0.070^{\mathrm{ab}}$ & 0.006 & 0.045 \\
\hline 65-day-old & 4.364 & 4.207 & 4.062 & 4.244 & 0.085 & 0.118 \\
\hline 95-day-old & 5.141 & 4.824 & 5.001 & 4.759 & 0.103 & 0.056 \\
\hline 125-day-old & 4.670 & 4.440 & 4.687 & 4.621 & 0.102 & 0.345 \\
\hline
\end{tabular}


C18:1n9c

\begin{tabular}{|c|c|c|c|c|c|c|}
\hline 65-day-old & $8.753^{\mathrm{a}}$ & $8.813^{\mathrm{a}}$ & $8.023^{\mathrm{b}}$ & $8.805^{\mathrm{a}}$ & 0.198 & 0.021 \\
\hline 95-day-old & $8.820^{\mathrm{ab}}$ & $8.592^{\mathrm{b}}$ & $9.663^{\mathrm{a}}$ & $8.894^{\mathrm{ab}}$ & 0.256 & 0.035 \\
\hline 125-day-old & 9.722 & 9.520 & 9.567 & 10.171 & 0.358 & 0.610 \\
\hline \multicolumn{7}{|l|}{$\mathrm{C} 18: 1 \mathrm{n} 9 \mathrm{t}$} \\
\hline 65-day-old & 0.036 & 0.036 & 0.035 & 0.033 & 0.001 & 0.500 \\
\hline 95-day-old & 0.034 & 0.032 & 0.035 & 0.032 & 0.002 & 0.538 \\
\hline 125-day-old & $0.042^{\mathrm{a}}$ & $0.035^{\mathrm{b}}$ & $0.035^{\mathrm{b}}$ & $0.036^{\mathrm{b}}$ & 0.002 & 0.019 \\
\hline \multicolumn{7}{|l|}{ C18:2n6c } \\
\hline 65-day-old & $4.135^{\mathrm{b}}$ & $4.499^{\mathrm{a}}$ & $4.626^{\mathrm{a}}$ & $4.008^{b}$ & 0.107 & 0.001 \\
\hline 95-day-old & 3.179 & 3.503 & 3.242 & 3.165 & 0.104 & 0.101 \\
\hline 125-day-old & $2.603^{\mathrm{a}}$ & $2.306^{\mathrm{ab}}$ & $2.405^{\mathrm{ab}}$ & $2.150^{\mathrm{b}}$ & 0.105 & 0.037 \\
\hline \multicolumn{7}{|l|}{ C20:0 } \\
\hline 65-day-old & $0.063^{\mathrm{a}}$ & $0.064^{\mathrm{a}}$ & $0.051^{\mathrm{b}}$ & $0.068^{\mathrm{a}}$ & 0.003 & 0.001 \\
\hline 95-day-old & 0.070 & 0.074 & 0.075 & 0.068 & 0.003 & 0.190 \\
\hline 125-day-old & 0.063 & 0.057 & 0.061 & 0.064 & 0.003 & 0.387 \\
\hline \multicolumn{7}{|l|}{ C20:1 } \\
\hline 65-day-old & $0.204^{\mathrm{b}}$ & $0.223^{\mathrm{ab}}$ & $0.181^{\mathrm{c}}$ & $0.241^{\mathrm{a}}$ & 0.008 & $<.0001$ \\
\hline 95-day-old & $0.303^{\mathrm{a}}$ & $0.223^{c}$ & $0.296^{\mathrm{a}}$ & $0.263^{\mathrm{b}}$ & 0.010 & $<.0001$ \\
\hline 125-day-old & 0.097 & 0.088 & 0.090 & 0.085 & 0.003 & 0.139 \\
\hline \multicolumn{7}{|l|}{$\mathrm{C} 20: 2$} \\
\hline 65-day-old & 0.163 & 0.155 & 0.143 & 0.156 & 0.005 & 0.059 \\
\hline 95-day-old & 0.153 & 0.138 & 0.148 & 0.138 & 0.006 & 0.267 \\
\hline 125-day-old & 0.105 & 0.091 & 0.091 & 0.088 & 0.005 & 0.097 \\
\hline \multicolumn{7}{|l|}{ C20:3n6 } \\
\hline 65-day-old & 0.101 & 0.108 & 0.114 & 0.116 & 0.005 & 0.241 \\
\hline 95-day-old & 0.080 & 0.090 & 0.073 & 0.087 & 0.006 & 0.146 \\
\hline 125-day-old & 0.072 & 0.073 & 0.078 & 0.068 & 0.006 & 0.700 \\
\hline \multicolumn{7}{|l|}{$\mathrm{C} 20: 4 \mathrm{n} 6$} \\
\hline 65-day-old & 0.858 & 0.841 & 0.936 & 0.790 & 0.069 & 0.522 \\
\hline 95-day-old & $0.512^{\mathrm{b}}$ & $0.762^{\mathrm{a}}$ & $0.499^{\mathrm{b}}$ & $0.614^{\mathrm{b}}$ & 0.049 & 0.002 \\
\hline 125-day-old & 0.521 & 0.562 & 0.588 & 0.448 & 0.051 & 0.274 \\
\hline \multicolumn{7}{|l|}{$\mathrm{C} 24: 0$} \\
\hline 65-day-old & $0.052^{\mathrm{b}}$ & $0.056^{\mathrm{b}}$ & $0.074^{\mathrm{a}}$ & $0.054^{\mathrm{b}}$ & 0.004 & 0.002 \\
\hline 95-day-old & $0.051^{\mathrm{a}}$ & $0.055^{\mathrm{a}}$ & $0.036^{\mathrm{b}}$ & $0.046^{\mathrm{ab}}$ & 0.004 & 0.010 \\
\hline 125-day-old & 0.048 & 0.054 & 0.057 & 0.057 & 0.004 & 0.401 \\
\hline \multicolumn{7}{|l|}{ SFA } \\
\hline 65-day-old & $13.267^{\mathrm{a}}$ & $13.245^{\mathrm{a}}$ & $12.506^{\mathrm{b}}$ & $13.271^{\mathrm{a}}$ & 0.219 & 0.049 \\
\hline 95-day-old & 14.218 & 13.855 & 14.391 & 13.757 & 0.234 & 0.204 \\
\hline 125-day-old & 13.712 & 12.881 & 13.271 & 13.111 & 0.393 & 0.496 \\
\hline \multicolumn{7}{|l|}{ UFA } \\
\hline 65-day-old & 15.777 & 15.921 & 15.444 & 15.608 & 0.226 & 0.482 \\
\hline
\end{tabular}




\begin{tabular}{lcccccc} 
95-day-old & $14.318^{\mathrm{b}}$ & $14.175^{\mathrm{b}}$ & $15.186^{\mathrm{a}}$ & $14.553^{\mathrm{b}}$ & 0.161 & 0.001 \\
125-day-old & 14.061 & 13.697 & 13.528 & 13.803 & 0.302 & 0.604 \\
MUFA & & & & & & \\
65-day-old & 10.144 & 10.901 & 9.373 & 10.512 & 0.447 & 0.119 \\
95-day-old & $9.857^{\mathrm{b}}$ & $9.568^{\mathrm{b}}$ & $10.94^{\mathrm{a}}$ & $10.084^{\mathrm{b}}$ & 0.267 & 0.007 \\
125-day-old & 10.761 & 10.465 & 10.475 & 10.87 & 0.405 & 0.863 \\
PUFA & & & & & & \\
65-day-old & $5.404^{\mathrm{b}}$ & $6.389^{\mathrm{a}}$ & $6.400^{\mathrm{a}}$ & $5.343^{\mathrm{b}}$ & 0.314 & 0.027 \\
95-day-old & $3.891^{\mathrm{b}}$ & $4.587^{\mathrm{a}}$ & $4.094^{\mathrm{ab}}$ & $4.198^{\mathrm{ab}}$ & 0.156 & 0.028 \\
125-day-old & 3.300 & 3.232 & 3.192 & 2.933 & 0.215 & 0.674 \\
PUFA/SFA & & & & & & \\
65-day-old & 0.408 & 1.164 & 0.485 & 0.409 & 0.311 & 0.267 \\
95-day-ol & 0.276 & 0.328 & 0.283 & 0.307 & 0.015 & 0.082 \\
125-day-old & 0.246 & 0.244 & 0.241 & 0.226 & 0.020 & 0.913 \\
\hline
\end{tabular}

1008 Data are presented as means with pooled SEM. Values in the same row with different 1009 superscript letters were significantly different $(P<0.05)$ The replicates per group at 65 1010 and 95-day-old were 8. At 125-day-old, the replicates of the control group, antibiotic 1011 group, probiotics group, and synbiotics group are 8, 6, 8, and 6, respectively.

1012 SFA, saturated fatty acid; UFA, Unsaturated fatty acid; MUFA, monounsaturated fatty 1013 acid; PUFA, polyunsaturated fatty acids. SFA, including C10:0, C12:0, C14:0, C15:0, 1014 C16:0, C17:0, C18:0, C20:0, and C24:0. UFA, including C16:1, C18:1n9c, C18:1n9t, 1015 C18:2n6c, C18:3n3, C20:1, C20:2, C20:3n6, and C20:4n6. MUFA, including C16:1, $1016 \mathrm{C} 18: 1 n 9 \mathrm{c}, \mathrm{C} 18: 1 \mathrm{n} 9 \mathrm{t}$, and C20:1. PUFA, including C18:2n6c, C18:3n3, C20:2, C20:3n6, 1017 and $\mathrm{C} 20: 4 \mathrm{n} 6$. 
1019 Effects of probiotics or synbiotics addition in sows' diets on plasma biochemical 1020 parameters of offspring pigs

\begin{tabular}{|c|c|c|c|c|c|c|}
\hline Item & $\begin{array}{c}\text { Control } \\
\text { group }\end{array}$ & $\begin{array}{c}\text { Antibiotic } \\
\text { group }\end{array}$ & $\begin{array}{c}\text { Probiotics } \\
\text { group }\end{array}$ & $\begin{array}{c}\text { Synbiotics } \\
\text { group }\end{array}$ & SEM & $\begin{array}{c}P \\
\text { values }\end{array}$ \\
\hline \multicolumn{7}{|l|}{ ALT (U/L) } \\
\hline 65-day-old & 58.79 & 56.28 & 56.81 & 59.15 & 2.369 & 0.782 \\
\hline 95-day-old & $54.74^{\mathrm{b}}$ & $54.22^{\mathrm{b}}$ & $59.60^{\mathrm{b}}$ & $78.33^{\mathrm{a}}$ & 4.811 & 0.004 \\
\hline 125-day-old & 51.77 & 48.18 & 50.76 & 48.10 & 3.847 & 0.873 \\
\hline \multicolumn{7}{|l|}{ ALP (U/L) } \\
\hline 65-day-old & 148.88 & 164.00 & 134.57 & 155.50 & 8.351 & 0.108 \\
\hline 95-day-old & 123.63 & 127.17 & 118.50 & 122.83 & 10.524 & 0.951 \\
\hline 125-day-old & $162.88^{\mathrm{ab}}$ & $197.50^{\mathrm{a}}$ & $142.83^{b}$ & $123.00^{\mathrm{b}}$ & 13.740 & 0.010 \\
\hline \multicolumn{7}{|l|}{$\alpha$-AMS (U/L) } \\
\hline 65-day-old & $2260.50^{\mathrm{a}}$ & $1851.40^{\mathrm{b}}$ & $1842.17^{b}$ & $1852.33^{b}$ & 76.887 & 0.001 \\
\hline 95-day-old & 2186.71 & 2074.40 & 2176.80 & 2271.60 & 80.523 & 0.405 \\
\hline 125-day-old & $2306.00^{\mathrm{b}}$ & $2783.00^{\mathrm{a}}$ & $2438.25^{\mathrm{ab}}$ & $2806.00^{\mathrm{a}}$ & 121.075 & 0.016 \\
\hline \multicolumn{7}{|l|}{ AST (U/L) } \\
\hline 65-day-old & 59.75 & 56.40 & 73.71 & 53.83 & 6.181 & 0.129 \\
\hline 95-day-old & $73.30^{\mathrm{a}}$ & $53.80^{\mathrm{bc}}$ & $47.33^{\mathrm{c}}$ & $63.75^{\mathrm{ab}}$ & 3.606 & $<.0001$ \\
\hline 125-day-old & $65.17^{\mathrm{a}}$ & $47.20^{\mathrm{b}}$ & $49.50^{\mathrm{b}}$ & $67.50^{\mathrm{a}}$ & 5.292 & 0.023 \\
\hline \multicolumn{7}{|l|}{ CHE (g/L) } \\
\hline 65-day-old & $534.63^{\mathrm{a}}$ & $540.33^{\mathrm{a}}$ & $420.29^{b}$ & $548.33^{\mathrm{a}}$ & 16.605 & $<.0001$ \\
\hline 95-day-old & $516.25^{\mathrm{a}}$ & $542.83^{\mathrm{a}}$ & $427.60^{\mathrm{b}}$ & $457.71^{b}$ & 15.986 & $<.0001$ \\
\hline 125-day-old & 467.67 & 475.25 & 445.50 & 487.25 & 13.724 & 0.203 \\
\hline \multicolumn{7}{|l|}{ LDH (U/L) } \\
\hline 65-day-old & $416.75^{b}$ & $332.20^{c}$ & $503.67^{\mathrm{a}}$ & $378.17^{\mathrm{bc}}$ & 18.040 & $<.0001$ \\
\hline 95-day-old & $465.71^{\mathrm{a}}$ & $374.43^{b}$ & $322.67^{b}$ & $437.67^{\mathrm{a}}$ & 19.825 & $<.0001$ \\
\hline 125-day-old & $475.57^{\mathrm{a}}$ & $383.25^{\mathrm{b}}$ & $383.29^{\mathrm{b}}$ & $411.25^{\mathrm{ab}}$ & 26.291 & 0.042 \\
\hline \multicolumn{7}{|l|}{$\operatorname{ALB}(\mathrm{g} / \mathrm{L})$} \\
\hline 65-day-old & $41.23^{\mathrm{a}}$ & $35.54^{\mathrm{b}}$ & $41.21^{\mathrm{a}}$ & $40.50^{\mathrm{a}}$ & 0.643 & $<.0001$ \\
\hline 95-day-old & 40.45 & 39.46 & 40.58 & 40.48 & 0.657 & 0.596 \\
\hline 125-day-old & 43.86 & 44.53 & 45.18 & 43.93 & 0.915 & 0.677 \\
\hline \multicolumn{7}{|c|}{$\mathrm{AMM}(\mu \mathrm{mol} / \mathrm{L})$} \\
\hline 65-day-old & 167.93 & 159.24 & 203.50 & 189.87 & 14.293 & 0.137 \\
\hline 95-day-old & $265.37^{\mathrm{a}}$ & $236.36^{\mathrm{a}}$ & $171.86^{\mathrm{b}}$ & $229.62^{\mathrm{a}}$ & 17.090 & 0.005 \\
\hline 125-day-old & $332.90^{\mathrm{a}}$ & $128.30^{\mathrm{d}}$ & $198.58^{c}$ & $269.55^{b}$ & 21.299 & $<.0001$ \\
\hline \multicolumn{7}{|l|}{$\mathrm{TP}(\mathrm{g} / \mathrm{L})$} \\
\hline 65-day-old & 65.00 & 66.62 & 65.13 & 67.52 & 0.765 & 0.078 \\
\hline 95-day-old & $73.68^{\mathrm{ab}}$ & $73.68^{\mathrm{ab}}$ & $74.63^{\mathrm{a}}$ & $70.82^{b}$ & 0.939 & 0.043 \\
\hline
\end{tabular}




\begin{tabular}{lcccccc} 
125-day-old & $72.76^{\mathrm{a}}$ & $68.90^{\mathrm{b}}$ & $73.78^{\mathrm{a}}$ & $73.10^{\mathrm{a}}$ & 0.833 & 0.002 \\
UN (mmol/L) & & & & & & \\
65-day-old & 3.10 & 3.20 & 3.18 & 2.87 & 0.341 & 0.901 \\
95-day-old & $3.56^{\mathrm{a}}$ & $3.60^{\mathrm{a}}$ & $2.42^{\mathrm{c}}$ & $3.14^{\mathrm{b}}$ & 0.127 & $<.0001$ \\
125-day-old & $3.47^{\mathrm{ab}}$ & $3.98^{\mathrm{a}}$ & $3.93^{\mathrm{a}}$ & $3.35^{\mathrm{b}}$ & 0.158 & 0.020 \\
HDL-C (mmol/L) & & & & & & \\
65-day-old & $0.76^{\mathrm{b}}$ & $0.75^{\mathrm{b}}$ & $0.74^{\mathrm{b}}$ & $0.88^{\mathrm{a}}$ & 0.033 & 0.019 \\
95-day-old & 1.07 & 1.11 & 1.05 & 1.01 & 0.036 & 0.292 \\
125-day-old & $1.10^{\mathrm{b}}$ & $1.22^{\mathrm{a}}$ & $1.23^{\mathrm{a}}$ & $1.09^{\mathrm{b}}$ & 0.036 & 0.010 \\
LDL-C (mmol/L) & & & & & & \\
65-day-old & $1.28^{\mathrm{b}}$ & $1.08^{\mathrm{c}}$ & $1.26^{\mathrm{b}}$ & $1.50^{\mathrm{a}}$ & 0.050 & $<.0001$ \\
95-day-old & 1.57 & 1.64 & 1.66 & 1.60 & 0.084 & 0.860 \\
125-day-old & 1.53 & 1.26 & 1.53 & 1.43 & 0.073 & 0.052 \\
TC (mmol/L) & & & & & & \\
65-day-old & $2.37^{\mathrm{b}}$ & $2.12^{\mathrm{c}}$ & $2.31^{\mathrm{b}}$ & $2.53^{\mathrm{a}}$ & 0.053 & $<.0001$ \\
95-day-old & 2.68 & 2.90 & 2.85 & 2.83 & 0.073 & 0.199 \\
125-day-old & $2.78^{\mathrm{ab}}$ & $2.59^{\mathrm{b}}$ & $3.05^{\mathrm{a}}$ & $2.78^{\mathrm{ab}}$ & 0.082 & 0.004 \\
TG (mmol/L) & & & & & & \\
65-day-old & 0.49 & 0.48 & 0.49 & 0.53 & 0.034 & 0.734 \\
95-day-old & $0.76^{\mathrm{a}}$ & $0.60^{\mathrm{ab}}$ & $0.63^{\mathrm{ab}}$ & $0.51^{\mathrm{b}}$ & 0.047 & 0.009 \\
125-day-old & $0.62^{\mathrm{b}}$ & $0.61^{\mathrm{b}}$ & $0.56^{\mathrm{b}}$ & $0.82^{\mathrm{a}}$ & 0.034 & $<.0001$ \\
GLU (mmol/L) & & & & & & \\
65-day-old & $5.30^{\mathrm{a}}$ & $5.12^{\mathrm{ab}}$ & $5.30^{\mathrm{a}}$ & $4.66^{\mathrm{b}}$ & 0.176 & 0.049 \\
95-day-old & $6.40^{\mathrm{a}}$ & $4.66^{\mathrm{b}}$ & $5.18^{\mathrm{b}}$ & $4.78^{\mathrm{b}}$ & 0.246 & $<.0001$ \\
125-day-old & 4.48 & $4.92^{\mathrm{b}}$ & 4.66 & 4.80 & 0.161 & 0.261 \\
\hline
\end{tabular}

1021 Data are presented as means with pooled SEM. Values in the same row with different 1022 superscript letters were significantly different $(P<0.05)$ The replicates per group at 65 1023 and 95-day-old were 8. At 125-day-old, the replicates of the control group, antibiotic 1024 group, probiotics group, and synbiotics group are 8, 6, 8, and 6, respectively.

1025 ALT, alanine aminotransferase; ALP, alkaline phosphatase; $\alpha$-AMS, $\alpha$-amylase; AST, 1026 aspartate aminotransferase; CHE, cholinesterase; LDH, lactate dehydrogenase; ALB, 1027 albumin; AMM, ammonia; TP, total protein; UN, urea nitrogen; HDL-C, high density 1028 lipoprotein-cholesterol; LDL-C, low density lipoprotein-cholesterol; TC, total 1029 cholesterol; TG, triglyceride; GLU, glucose. 
1031 Effects of probiotics or synbiotics addition in sows' diets on plasma free amino acid of 1032 offspring pigs (nmol/mL)

\begin{tabular}{|c|c|c|c|c|c|c|}
\hline Item & $\begin{array}{c}\text { Control } \\
\text { group }\end{array}$ & $\begin{array}{c}\text { Antibiotic } \\
\text { group }\end{array}$ & $\begin{array}{c}\text { Probiotics } \\
\text { group }\end{array}$ & $\begin{array}{c}\text { Synbiotics } \\
\text { group }\end{array}$ & SEM & $P$ values \\
\hline \multicolumn{7}{|l|}{ 1-Mehis } \\
\hline 65-day-old & 0.85 & 0.95 & 0.50 & 0.90 & 0.147 & 0.157 \\
\hline 95-day-old & $6.13^{b}$ & $8.96^{\mathrm{a}}$ & $5.06^{\mathrm{b}}$ & $6.70^{\mathrm{b}}$ & 0.626 & 0.001 \\
\hline 125-day-old & 0.93 & 0.89 & 0.44 & 1.16 & 0.201 & 0.095 \\
\hline \multicolumn{7}{|l|}{ 3-Mehis } \\
\hline 65-day-old & 12.38 & 11.64 & 11.69 & 12.13 & 0.766 & 0.885 \\
\hline 95-day-old & 14.09 & 13.74 & 12.71 & 15.27 & 0.730 & 0.123 \\
\hline 125-day-old & 13.92 & 15.41 & 17.17 & 16.37 & 1.082 & 0.146 \\
\hline \multicolumn{7}{|l|}{ Ala } \\
\hline 65-day-old & $419.55^{\mathrm{a}}$ & $445.57^{\mathrm{a}}$ & $323.57^{b}$ & $391.40^{\mathrm{ab}}$ & 24.723 & 0.011 \\
\hline 95-day-old & $358.50^{\mathrm{a}}$ & $252.02^{\mathrm{b}}$ & $296.22^{\mathrm{ab}}$ & $347.86^{\mathrm{a}}$ & 18.048 & 0.001 \\
\hline 125-day-old & $312.99^{b}$ & $393.20^{\mathrm{a}}$ & $301.66^{\mathrm{b}}$ & $284.56^{\mathrm{b}}$ & 20.815 & 0.009 \\
\hline \multicolumn{7}{|l|}{ Ans } \\
\hline 65-day-old & 1.05 & 1.04 & 0.98 & 0.88 & 0.105 & 0.682 \\
\hline 95-day-old & $0.48^{\mathrm{a}}$ & $0.46^{\mathrm{a}}$ & $0.51^{\mathrm{a}}$ & $0.36^{\mathrm{b}}$ & 0.028 & 0.005 \\
\hline 125-day-old & $22.53^{\mathrm{c}}$ & $55.86^{\mathrm{a}}$ & $35.01^{\mathrm{b}}$ & $21.56^{\mathrm{c}}$ & 2.124 & $<.0001$ \\
\hline \multicolumn{7}{|l|}{ Arg } \\
\hline 65-day-old & 70.36 & 79.78 & 83.70 & 88.64 & 4.783 & 0.070 \\
\hline 95-day-old & $89.22^{\mathrm{ab}}$ & $67.25^{\mathrm{b}}$ & $69.73^{b}$ & $102.12^{\mathrm{a}}$ & 6.953 & 0.004 \\
\hline 125-day-old & $84.84^{\mathrm{b}}$ & $105.52^{\mathrm{a}}$ & $85.15^{\mathrm{b}}$ & $88.29^{b}$ & 3.540 & 0.001 \\
\hline \multicolumn{7}{|l|}{ Asp } \\
\hline 65-day-old & 7.88 & 9.41 & 8.84 & 7.39 & 1.256 & 0.665 \\
\hline 95-day-old & 9.86 & 10.99 & 11.55 & 9.53 & 0.748 & 0.211 \\
\hline 125-day-old & $10.85^{\mathrm{a}}$ & $12.44^{\mathrm{a}}$ & $6.99^{b}$ & $10.34^{\mathrm{a}}$ & 0.679 & $<.0001$ \\
\hline \multicolumn{7}{|l|}{ Car } \\
\hline 65-day-old & 10.51 & 10.61 & 10.72 & 7.03 & 1.152 & 0.087 \\
\hline 95-day-old & $10.93^{\mathrm{a}}$ & $8.97^{\mathrm{a}}$ & $3.30^{\mathrm{b}}$ & $8.24^{\mathrm{a}}$ & 0.985 & $<.0001$ \\
\hline 125-day-old & 18.25 & 17.06 & 13.97 & 15.10 & 1.300 & 0.083 \\
\hline \multicolumn{7}{|l|}{ Cit } \\
\hline 65-day-old & $25.65^{\mathrm{c}}$ & $30.35^{\mathrm{b}}$ & $23.54^{\mathrm{c}}$ & $34.81^{\mathrm{a}}$ & 1.272 & $<.0001$ \\
\hline 95-day-old & $40.77^{\mathrm{a}}$ & $31.80^{\mathrm{b}}$ & $30.24^{\mathrm{b}}$ & $34.47^{b}$ & 1.829 & 0.002 \\
\hline 125-day-old & 38.50 & 34.22 & 40.66 & 34.89 & 2.474 & 0.229 \\
\hline \multicolumn{7}{|l|}{ Cysthi } \\
\hline 65-day-old & $13.04^{\mathrm{b}}$ & $7.55^{\mathrm{c}}$ & $13.52^{\mathrm{b}}$ & $18.79^{\mathrm{a}}$ & 0.927 & $<.0001$ \\
\hline 95-day-old & $6.05^{\mathrm{b}}$ & $6.69^{b}$ & $7.17^{\mathrm{ab}}$ & $8.37^{\mathrm{a}}$ & 0.437 & 0.006 \\
\hline
\end{tabular}




$\begin{array}{lcccccc}\text { 125-day-old } & 9.97^{\mathrm{b}} & 9.13^{\mathrm{b}} & 10.88^{\mathrm{ab}} & 13.89^{\mathrm{a}} & 1.027 & 0.036 \\ \text { Cys } & & & & & & \\ \text { 65-day-old } & 9.56 & 11.19 & 8.58 & 12.69 & 1.062 & 0.052 \\ \text { 95-day-old } & 94.43 & 93.56 & 59.16 & 70.89 & 14.719 & 0.264 \\ \text { 125-day-old } & 12.55 & 11.11 & 7.17 & 12.87 & 1.872 & 0.115 \\ \text { EOHNH2 } & & & & & & \\ \text { 65-day-old } & 0.27 & 0.31 & 0.25 & 0.28 & 0.031 & 0.558 \\ \text { 95-day-old } & 24.52^{\mathrm{b}} & 36.69^{\mathrm{a}} & 0.46^{\mathrm{c}} & 0.27^{\mathrm{c}} & 2.086 & <.0001 \\ \text { 125-day-old } & 5.09^{\mathrm{a}} & 5.31^{\mathrm{a}} & 5.90^{\mathrm{a}} & 2.95^{\mathrm{b}} & 0.522 & 0.006\end{array}$

Glu

$\begin{array}{lllllll}\text { 65-day-old } & 186.00 & 211.73 & 197.39 & 183.61 & 11.824 & 0.334\end{array}$

$\begin{array}{lllllll}\text { 95-day-old } & 207.52 & 175.66 & 213.62 & 215.32 & 11.319 & 0.066\end{array}$

125 -day-old $\quad 155.75^{\mathrm{a}} \quad 133.41^{\mathrm{b}} \quad 159.41^{\mathrm{a}} \quad 134.23^{\mathrm{b}} \quad 4.571 \quad<.0001$

Gly

$\begin{array}{lllllll}65-\text { day-old } & 525.00^{\mathrm{a}} & 441.15^{\mathrm{b}} & 417.84^{\mathrm{b}} & 517.45^{\mathrm{a}} & 22.405 & 0.003\end{array}$

$\begin{array}{lllllll}\text { 95-day-old } & 470.34 & 472.11 & 484.09 & 560.27 & 29.847 & 0.129\end{array}$

125 -day-old $\quad 566.31^{\mathrm{b}} \quad 744.00^{\mathrm{a}} \quad 517.49^{\mathrm{b}} \quad 582.66^{\mathrm{b}} \quad 20.194 \quad<.0001$

His

$\begin{array}{lcccccc}\text { 65-day-old } & 36.13^{\mathrm{bc}} & 38.06^{\mathrm{ab}} & 39.58^{\mathrm{a}} & 35.05^{\mathrm{c}} & 0.834 & 0.003 \\ \text { 95-day-old } & 43.72^{\mathrm{a}} & 38.14^{\mathrm{b}} & 37.98^{\mathrm{b}} & 40.04^{\mathrm{ab}} & 1.406 & 0.026 \\ \text { 125-day-old } & 44.72^{\mathrm{a}} & 47.79^{\mathrm{a}} & 39.29^{\mathrm{b}} & 44.59^{\mathrm{a}} & 1.074 & <.0001\end{array}$

Hylys

$\begin{array}{lcccccc}\text { 65-day-old } & 1.08^{\mathrm{b}} & 0.99^{\mathrm{b}} & 1.77^{\mathrm{a}} & 1.00^{\mathrm{b}} & 0.144 & 0.001 \\ \text { 95-day-old } & 0.55^{\mathrm{b}} & 0.21^{\mathrm{b}} & 0.31^{\mathrm{b}} & 17.46^{\mathrm{a}} & 0.545 & <.0001 \\ \text { 125-day-old } & 20.27 & 17.00 & 16.29 & 13.96 & 2.598 & 0.404 \\ \text { Hypro } & & & & & & \\ \text { 65-day-old } & 80.45^{\mathrm{a}} & 63.26^{\mathrm{b}} & 67.49^{\mathrm{b}} & 63.80^{\mathrm{b}} & 3.157 & 0.002 \\ \text { 95-day-old } & 37.70 & 27.34 & 31.12 & 40.87 & 3.707 & 0.062 \\ \text { 125-day-old } & 67.51 & 73.25 & 61.61 & 56.72 & 4.385 & 0.098\end{array}$

Ile

$\begin{array}{lllllll}65-\text { day-old } & 100.01^{\mathrm{a}} & 89.39^{\mathrm{b}} & 85.87^{\mathrm{b}} & 106.56^{\mathrm{a}} & 3.376 & 0.001\end{array}$

$\begin{array}{lllllll}\text { 95-day-old } & 90.11^{\mathrm{a}} & 72.10^{\mathrm{b}} & 68.44^{\mathrm{b}} & 75.76^{\mathrm{b}} & 3.811 & 0.002\end{array}$

$\begin{array}{lllllll}125 \text {-day-old } \quad 86.29^{\mathrm{b}} & 98.37^{\mathrm{ab}} & 95.59^{\mathrm{ab}} & 101.40^{\mathrm{a}} & 3.731 & 0.042\end{array}$

Leu

$\begin{array}{lllllll}65-\text { day-old } & 164.89^{\mathrm{a}} & 150.55^{\mathrm{ab}} & 141.18^{\mathrm{b}} & 157.55^{\mathrm{ab}} & 4.946 & 0.015\end{array}$

$\begin{array}{lllllll}95-\text { day-old } & 140.61^{\mathrm{a}} & 110.86^{\mathrm{b}} & 108.49^{\mathrm{b}} & 101.71^{\mathrm{b}} & 6.546 & 0.001\end{array}$

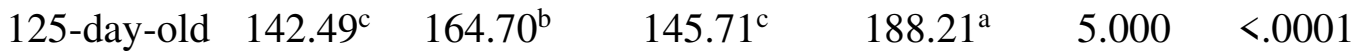

Lys

$\begin{array}{lllllll}\text { 65-day-old } & 143.17 & 132.49 & 136.97 & 143.94 & 6.986 & 0.619 \\ \text { 95-day-old } & 125.61 & 124.84 & 107.98 & 137.62 & 9.034 & 0.167\end{array}$ 


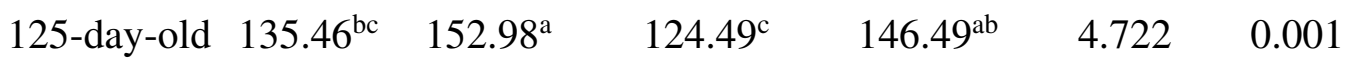

Met

$\begin{array}{lcccccc}\text { 65-day-old } & 15.68 & 15.23 & 14.20 & 14.48 & 0.603 & 0.306 \\ \text { 95-day-old } & 12.76 & 10.83 & 10.76 & 11.79 & 0.641 & 0.113 \\ \text { 125-day-old } & 12.73^{\mathrm{c}} & 16.16^{\mathrm{a}} & 14.10^{\mathrm{b}} & 12.84^{\mathrm{c}} & 0.305 & <.0001\end{array}$

Orn

$\begin{array}{lllllll}\text { 65-day-old } & 51.91 & 55.78 & 59.34 & 56.87 & 3.443 & 0.500 \\ \text { 95-day-old } & 56.21^{\mathrm{b}} & 40.61^{\mathrm{a}} & 53.07^{\mathrm{b}} & 64.72^{\mathrm{b}} & 4.032 & 0.002 \\ 125 \text {-day-old } & 68.98^{\mathrm{a}} & 55.47^{\mathrm{b}} & 43.97^{\mathrm{b}} & 56.39^{\mathrm{b}} & 3.736 & <.0001\end{array}$

Phe

$\begin{array}{lcccccc}\text { 65-day-old } & 81.15 & 85.83 & 78.38 & 79.57 & 3.381 & 0.436 \\ \text { 95-day-old } & 81.64 & 79.95 & 73.05 & 83.18 & 2.810 & 0.077 \\ \text { 125-day-old } & 90.72^{\mathrm{ab}} & 92.96^{\mathrm{a}} & 85.38^{\mathrm{b}} & 88.08^{\mathrm{ab}} & 1.540 & 0.009\end{array}$

Pro

$\begin{array}{lcccccc}\text { 65-day-old } & 173.12^{\mathrm{b}} & 214.35^{\mathrm{a}} & 163.76^{\mathrm{b}} & 188.85^{\mathrm{b}} & 7.593 & <.0001 \\ \text { 95-day-old } & 157.10 & 143.26 & 154.65 & 148.96 & 8.298 & 0.650 \\ \text { 125-day-old } & 183.79^{\mathrm{b}} & 224.84^{\mathrm{a}} & 162.65^{\mathrm{b}} & 160.26^{\mathrm{b}} & 11.179 & 0.002\end{array}$

Sar

$\begin{array}{lcccccc}\text { 65-day-old } & 8.53^{\mathrm{a}} & 3.72^{\mathrm{b}} & 4.13^{\mathrm{b}} & 6.10^{\mathrm{ab}} & 0.875 & 0.002 \\ \text { 95-day-old } & 0.41^{\mathrm{c}} & 0.66^{\mathrm{c}} & 6.67^{\mathrm{a}} & 2.08^{\mathrm{b}} & 0.381 & <.0001 \\ \text { 125-day-old } & 2.25 & 2.38 & 2.28 & 2.28 & 0.115 & 0.855\end{array}$

Ser

$\begin{array}{lcccccc}\text { 65-day-old } & 75.51 & 87.29 & 82.69 & 80.79 & 3.228 & 0.101 \\ \text { 95-day-old } & 81.57 & 75.69 & 78.11 & 75.35 & 2.589 & 0.318 \\ \text { 125-day-old } & 81.30^{\mathrm{b}} & 97.57^{\mathrm{a}} & 69.65^{\mathrm{c}} & 73.61^{\mathrm{c}} & 1.802 & <.0001\end{array}$

Tau

$\begin{array}{lllllll}\text { 65-day-old } & 133.56^{\mathrm{a}} & 108.96^{\mathrm{bc}} & 100.33^{\mathrm{c}} & 121.25^{\mathrm{ab}} & 5.264 & 0.001 \\ \text { 95-day-old } & 138.40^{\mathrm{a}} & 116.37^{\mathrm{b}} & 116.01^{\mathrm{b}} & 116.55^{\mathrm{b}} & 5.698 & 0.022 \\ \text { 125-day-old } & 137.88^{\mathrm{b}} & 153.35^{\mathrm{a}} & 133.68^{\mathrm{b}} & 128.73^{\mathrm{b}} & 5.074 & 0.021\end{array}$

Thr

$\begin{array}{lcccccc}\text { 65-day-old } & 116.70^{\mathrm{b}} & 151.48^{\mathrm{a}} & 108.88^{\mathrm{b}} & 117.32^{\mathrm{b}} & 7.145 & 0.001 \\ \text { 95-day-old } & 105.91 & 107.08 & 113.80 & 114.86 & 8.913 & 0.852 \\ \text { 125-day-old } & 119.87^{\mathrm{b}} & 147.49^{\mathrm{a}} & 111.62^{\mathrm{b}} & 113.26^{\mathrm{b}} & 4.004 & <.0001 \\ \text { Tyr } & & & & & & \\ \text { 65-day-old } & 50.03^{\mathrm{a}} & 47.53^{\mathrm{a}} & 24.34^{\mathrm{b}} & 47.37^{\mathrm{a}} & 4.762 & 0.002 \\ \text { 95-day-old } & 44.93 & 53.06 & 48.90 & 52.60 & 2.562 & 0.112 \\ \text { 125-day-old } & 62.07^{\mathrm{b}} & 67.95^{\mathrm{a}} & 60.31^{\mathrm{b}} & 60.48^{\mathrm{b}} & 1.552 & 0.008 \\ \text { Val } & & & & & & \\ \text { 65-day-old } & 249.16^{\mathrm{ab}} & 222.48^{\mathrm{b}} & 220.34^{\mathrm{b}} & 264.19^{\mathrm{a}} & 12.257 & 0.047 \\ \text { 95-day-old } & 213.22 & 183.85 & 205.35 & 209.81 & 8.517 & 0.089\end{array}$




\begin{tabular}{lcccccc} 
125-day-old & $237.37^{\mathrm{b}}$ & $283.85^{\mathrm{a}}$ & $257.01^{\mathrm{ab}}$ & $284.97^{\mathrm{a}}$ & 13.022 & 0.044 \\
$\alpha$-AAA & & & & & & \\
65-day-old & 65.81 & 56.64 & 67.93 & 57.40 & 4.768 & 0.247 \\
95-day-old & $60.05^{\mathrm{a}}$ & $45.61^{\mathrm{b}}$ & $47.63^{\mathrm{b}}$ & $45.07^{\mathrm{b}}$ & 2.733 & 0.002 \\
125-day-old & $55.04^{\mathrm{ab}}$ & $49.07^{\mathrm{ab}}$ & $57.68^{\mathrm{a}}$ & $44.23^{\mathrm{b}}$ & 3.369 & 0.049 \\
$\alpha$-ABA & & & & & & \\
65-day-old & $15.47^{\mathrm{b}}$ & $24.10^{\mathrm{a}}$ & $15.68^{\mathrm{b}}$ & $18.36^{\mathrm{ab}}$ & 2.277 & 0.042 \\
95-day-old & $12.16^{\mathrm{a}}$ & $4.47^{\mathrm{b}}$ & $0.66^{\mathrm{c}}$ & $4.87^{\mathrm{b}}$ & 1.147 & $<.0001$ \\
125-day-old & $2.68^{\mathrm{c}}$ & $3.45^{\mathrm{b}}$ & $3.70^{\mathrm{ab}}$ & $4.06^{\mathrm{a}}$ & 0.131 & $<.0001$ \\
$\beta$ - Ala & & & & & & \\
65-day-old & 8.33 & 5.87 & 6.00 & 7.30 & 0.763 & 0.096 \\
95-day-old & $8.88^{\mathrm{a}}$ & $3.91^{\mathrm{c}}$ & $2.70^{\mathrm{c}}$ & $6.33^{\mathrm{b}}$ & 0.555 & $<.0001$ \\
125-day-old & $6.91^{\mathrm{b}}$ & $8.60^{\mathrm{a}}$ & $6.97^{\mathrm{b}}$ & $7.85^{\mathrm{ab}}$ & 0.273 & $<.0001$ \\
$\beta$-AiBA & & & & & & \\
65-day-old & $0.52^{\mathrm{b}}$ & $1.43^{\mathrm{a}}$ & $0.33^{\mathrm{b}}$ & $1.35^{\mathrm{a}}$ & 0.084 & $<.0001$ \\
95-day-old & $0.66^{\mathrm{c}}$ & $2.55^{\mathrm{a}}$ & $1.72^{\mathrm{b}}$ & $1.73^{\mathrm{b}}$ & 0.196 & $<.0001$ \\
125-day-old & $0.61^{\mathrm{b}}$ & $1.05^{\mathrm{a}}$ & $0.59^{\mathrm{b}}$ & $0.37^{\mathrm{c}}$ & 0.054 & $<.0001$ \\
$\gamma$-ABA & & & & & & \\
65-day-old & $0.25^{\mathrm{b}}$ & $0.21^{\mathrm{b}}$ & $0.16^{\mathrm{b}}$ & $0.59^{\mathrm{a}}$ & 0.041 & $<.0001$ \\
95-day-old & $0.67^{\mathrm{a}}$ & $0.23^{\mathrm{b}}$ & $0.18^{\mathrm{b}}$ & $0.16^{\mathrm{b}}$ & 0.060 & $<.0001$ \\
125-day-old & 1.81 & 1.89 & 1.66 & 1.64 & 0.115 & 0.374 \\
\hline
\end{tabular}

1033 Data are presented as means with pooled SEM. Values in the same row with different

1034 superscript letters were significantly different $(P<0.05)$ The replicates per group at 65 1035 and 95-day-old were 8. At 125-day-old, the replicates of the control group, antibiotic 1036 group, probiotics group, and synbiotics group are 8, 6, 8, and 6, respectively.

1037 1-Mehis, 1-methyl-histidine; 3-Mehis, 3-methyl-histidine; Ala, alanine; Ans, anserine; 1038 Arg, arginine; Asp, aspartate; Car, carnosine; Cit, citrulline; Cysthi, cystathionine; Cys, 1039 cysteine; EOHNH2, ethanolamine; Glu, glutamate; Gly, glycine; His, histidine; Hylys, 1040 hydroxy-lysine; Hypro, hydroxy-proline; Ile, isoleucine; Leu, leucine; Lys, lysine; Met, 1041 methionine; Orn, ornithine; Phe, phenylalanine; Pro, proline; Sar, sarcosine; Ser, serine; 1042 Tau, taurine; Thr, threonine; Tyr, tyrosine; Val, valine; $\alpha$-AAA, $\alpha$-aminoadipic acid; $\alpha$ 1043 ABA, $\alpha$-amino-n-butyric acid; $\beta$-Ala, $\beta$-alanine; $\beta$-AiBA, $\beta$-aminoisobutyric acid; and $1044 \gamma$-ABA, $\gamma$-amino-n-butyric acid. 


\section{Supplementary Files}

This is a list of supplementary files associated with this preprint. Click to download.

- SupplementaryMaterials.pdf 